\title{
Thermodynamic Analysis of Dual-Mode Scramjet Engine Operation and Performance
}

\author{
David Riggins ${ }^{1}$, Regan Tackett ${ }^{2}$, Trent Taylor ${ }^{3}$ \\ University of Missouri - Rolla, Rolla, MO 65409 \\ and \\ Aaron Auslender ${ }^{4}$ \\ NASA Langley Research Center, Hampton, Virginia, 23669
}

\begin{abstract}
Recent analytical advances in understanding the performance continuum (the thermodynamic spectrum) for air-breathing engines based on fundamental second-law considerations have clarified scramjet and ramjet operation, performance, and characteristics. Second-law based analysis is extended specifically in this work to clarify and describe the performance characteristics for dual-mode scramjet operation in the mid-speed range of flight Mach 4 to 7 . This is done by a fundamental investigation of the complex but predictable interplay between heat release and irreversibilities in such an engine; results demonstrate the flow and performance character of the dual mode regime and of dual mode transition behavior. Both analytical and computational (multi-dimensional CFD) studies of sample dual-mode flow-fields are performed in order to demonstrate the second-law capability and performance and operability issues. The impact of the dual-mode regime is found to be characterized by decreasing overall irreversibility with increasing heat release, within the operability limits of the system.
\end{abstract}

\section{Nomenclature}

$\begin{array}{lll}A\left(\mathrm{~m}^{2}\right) & = & \text { cross-sectional area } \\ a(\mathrm{~m} / \mathrm{s}) & = & \text { ambient speed of sound } \\ C_{P}(\mathrm{~J} / \mathrm{kgK}) & = & \text { specific heat at constant pressure } \\ C R & = & \text { inlet contraction ratio } \\ f & = & \text { fuel-air ratio } \\ F_{x}(\mathrm{~N}) & = & \text { thrust } \\ g_{0}\left(\mathrm{~m} / \mathrm{s}^{2}\right) & = & \text { gravitational acceleration } \\ H_{p r o p}(\mathrm{~J} / \mathrm{kg}) & = & \text { fuel heating value } \\ I_{s p}(\mathrm{~s}) & = & \text { engine specific impulse } \\ L_{c}(\mathrm{~m}) & = & \text { combustor length } \\ \operatorname{Mach} & = & \text { Mach number } \\ \dot{m}(\mathrm{~kg} / \mathrm{s}) & = & \text { mass flow rate } \\ P\left(\mathrm{~N} / \mathrm{m}^{2}\right) & = & \text { static pressure } \\ P_{t}\left(\mathrm{~N} / \mathrm{m}^{2}\right) & = & \text { total pressure } \\ Q(\mathrm{~J} / \mathrm{kg}) & = & \text { heat per mass } \\ R(\mathrm{~J} / \mathrm{kgK}) & = & \text { specific gas constant } \\ S_{i r r}(i \rightarrow e) & = & \text { entropy per mass generated by irreversibilities/non-ideal heat addition } \\ T(\mathrm{~K}) & = & \text { static temperature } \\ T_{t}(\mathrm{~K}) & = & \text { total temperature } \\ U(\mathrm{~m} / \mathrm{s}) & = & \text { flow velocity }\end{array}$

${ }^{1}$ Professor of Aerospace Engineering, Mechanical and Aerospace Engineering, Senior Member AIAA.

${ }^{2}$ Graduate Research Assistant, Mechanical and Aerospace Engineering, Student Member AIAA.

${ }^{3}$ Graduate Research Assistant, Mechanical and Aerospace Engineering, Student Member AIAA.

${ }^{4}$ Research Aerospace Engineer, Hypersonic Propulsion Branch. 


\begin{tabular}{|c|c|c|}
\hline$x(m)$ & $=$ & axial distance from isolator entra \\
\hline$\gamma$ & $=$ & ratio of specific heats \\
\hline$\pi_{d}$ & $=$ & inlet total pressure recovery \\
\hline \multicolumn{3}{|c|}{ subscripts: } \\
\hline$c i$ & $=$ & combustor entrance/isolator exit \\
\hline$c e$ & $=$ & combustor exit \\
\hline$e$ & $=$ & engine exit \\
\hline eff & $=$ & effective (as in area ratio) \\
\hline$i$ & $=$ & inlet (engine) entrance \\
\hline 2 & $=$ & isolator entrance/inlet exit \\
\hline
\end{tabular}

\section{Introduction}

cramjet engine operation above a flight Mach number of around 7 or 8 is characterized by predominantly $\checkmark$ supersonic flow throughout the combustor. Areas of recirculation are generally small and are mainly confined to the aft surfaces of intrusive fuel injectors or associated with very local regions around flush-wall jets or rearward-facing surfaces. There is little upstream interaction in such a flow; limited interaction may occur due to information propagation upstream through relatively thin wall boundary layers, but this limited interaction does not affect the bulk upstream flow in any significant fashion. The critical ratio of heating rate caused by fuel-air combustion in the burner to entering total enthalpy rate is very small. This fact results in low pressure rises in the downstream burner (even with modest cross-sectional area increases) with the result that large-scale sub-sonic (or separated flow) simply is not established. The combustor entrance conditions are then essentially de-coupled from the flow-field within the combustor. Furthermore, the degree of diffusion throughout the inlet/combustor system is not sufficient to cause the flow Mach number (even within the combustor) to approach unity, hence the issue of choking and engine unstart is generally avoided. For the high-speed range, then, there is little ambiguity (although considerable challenge) for the engineer, at least in terms of understanding the broad design issues, requirements, and dominant flow features for the scramjet (in terms of predicting and analyzing performance and operability).

As flight Mach number is lowered below Mach 7 for a scramjet engine, some significant effects drastically change flow character, engine performance, and engine operability. The ratio of heating rate (due to fuel-air combustion) to entering total enthalpy rate becomes large. Significant pressure rise is experienced in the combustor. This pressure rise due to heat release is coupled with the decrease of the Mach number in the combustor so that Mach 1 (thermal choking) can result. Eventually, the flow can back-pressure enough such that significant interaction can occur upstream of the fuel injection location/combustor entrance; this interaction develops as an upstream oblique shock train with associated large recirculation (or low velocity) regions adjacent to walls. A highspeed scramjet operated at such conditions ('mid-speed' flight Mach numbers) will have this phenomena immediately propagate into the inlet. Due to the inherent instability associated with maintaining this shock system in a converging flowpath, inlet/engine unstart will result. For this reason, the component known as an isolator is generally incorporated between inlet and combustor for mid-speed scramjets - this component buffers the inlet from upstream propagating interaction from the combustor. The oblique shock system and associated pattern of recirculation regions will stabilize in the isolator such that started engine operation is possible, even with extensive upstream interaction (provided the isolator is long enough). Several other techniques can also be used including 1) backward facing steps at the entrance of the combustor proper or at various locations along the combustor (these tend to isolate or stabilize recirculation and slow the development of extensive upstream interactions), 2) diverging combustor walls in order to relieve the combustion-generated pressure rise, delay the development of a possible thermal choke, and facilitate reestablishment of supersonic flow subsequent to thermal choking and 3) axially staged injection which can 'distribute' heat release appropriate to combustor geometry and varying inflow conditions.

The variance of flow features observed for the scramjet combustor operated at mid-speed conditions is therefore astonishingly large. As examples: bulk flow may or may not remain supersonic, thermal choking may or may not occur, upstream recirculation bubbles may extend far downstream into the combustor proper (in fact, some rigspecific experimental data indicates recirculation blanketing the entire combustor), normal shocks can truncate the oblique shock train in the isolator or at the combustor entrance or the upstream flow itself can form an isolator aerodynamic throat. Such flows are highly complex, strongly coupled, massively elliptical in character, contain complex turbulence mechanisms and physics; they represent an extreme challenge for analysis, numerical simulation, or experimental work. 
It should be noted that the original concept and description of dual-mode operation appears in the work by Curran and Stull [1] who actually patented the concept. Subsequent work in the area of dual-mode design, analysis, and performance assessment includes the earlier work of Billig [2], Billig, Dugger, and Waltrup, [3], and Waltrup and Billig [4], [5]. These investigations ([2]-[5]) developed correlations based on experimental data and analysis and can be summarized as semi-empirical and are primarily useful for preliminary and trend descriptions. Such analysis has identified the importance and degree of downstream pressure rise, total temperature (i.e. enthalpy) ratios, inflow boundary layer characterization, etc. in terms of predicting necessary isolator length. These correlations generally work fairly well on simple geometries such as axi-symmetric and two-dimensional configurations (for which they were developed) but generally degrade in predictive capability for more complex configurations. Other studies involving experimental tests that have been reported on in the open literature include Komuro et al ([6] and [7]). Numerical simulations of these and similar tests have been conduced by Chinzei et al [8], Mizobuchi et al [9], Matsuo et al [10], and Rodriguez et al [11]. There have been numerous other CFD studies of dual-mode configurations and analysis of isolator physics in recent years. There are also several excellent basic descriptions of dual-mode behavior (explanation and illustration of the flow physics of modes and mode transition) such as found in Heiser and Pratt [12] who provide an extended and illuminating discussion of the problem and who examine the problem from fundamental principles and simplified gas dynamics and also in Ortwerth [13].

Although there is a great deal of information available regarding the characterization and behavior of dual mode systems, there has been little explicit and intentional work in the specific area of the second-law behavior of such systems. As will be shown subsequently (and also developed in previous works), the performance of a general $\mathrm{ram} / \mathrm{scramjet}$ engine is most fundamentally written in terms of the critical drivers of heat release, irreversibility (entropy increases due to irreversibility/non-ideal effects - or total pressure recovery), and engine/flight configuration parameters - the entire range of performance and operability can then be suitably and productively explored utilizing this basis. Therefore, the purpose of this paper is to report on a basic investigation into the second-law-driven behavior of dual-mode engines in all three regimes; supersonic, subsonic, and transition. Specifically, a fundamental analytical investigation coupled with a number of simple examples first demonstrates the required behavior for a dual-mode system on irreversible entropy generation rate versus heat release rate diagrams. Secondly, a computational investigation utilizing multi-dimensional CFD is shown and related directly to the analytical treatment. For the CFD, the approach taken here is to first use heating 'blocks' to emulate combustion in the combustor rather than actual fuel injection, mixing, and reaction in order to provide solid understanding of the second-law character of dual mode operation and to directly relate results to the prior analytical investigation. Subsequently, fuel injection and reaction in two-dimensional dual-mode systems will be utilized with accelerated mixing in order to study the interplay of entropy and performance in reduced order systems. Ultimately, the intent is to understand and apply the entropic analysis for 3-D isolator/combustor dual-mode scramjet operation.

\section{Dual Mode Engine Description: Geometry and Station Indices}

Figure 1 shows the engine schematic and station numbering system used for development of the analytical work detailed in subsequent sections of this paper. Station $\mathrm{i}$ is the inflow to the engine, assumed to have identical conditions as the free-stream, and station 2 is the inflow to the constant area isolator. Station ci is the inflow to the combustor (or equivalently the outflow from the isolator. Station ce is the outflow from the combustor exit or the inflow to the nozzle. Engine/vehicle exit plane is denoted by e. 

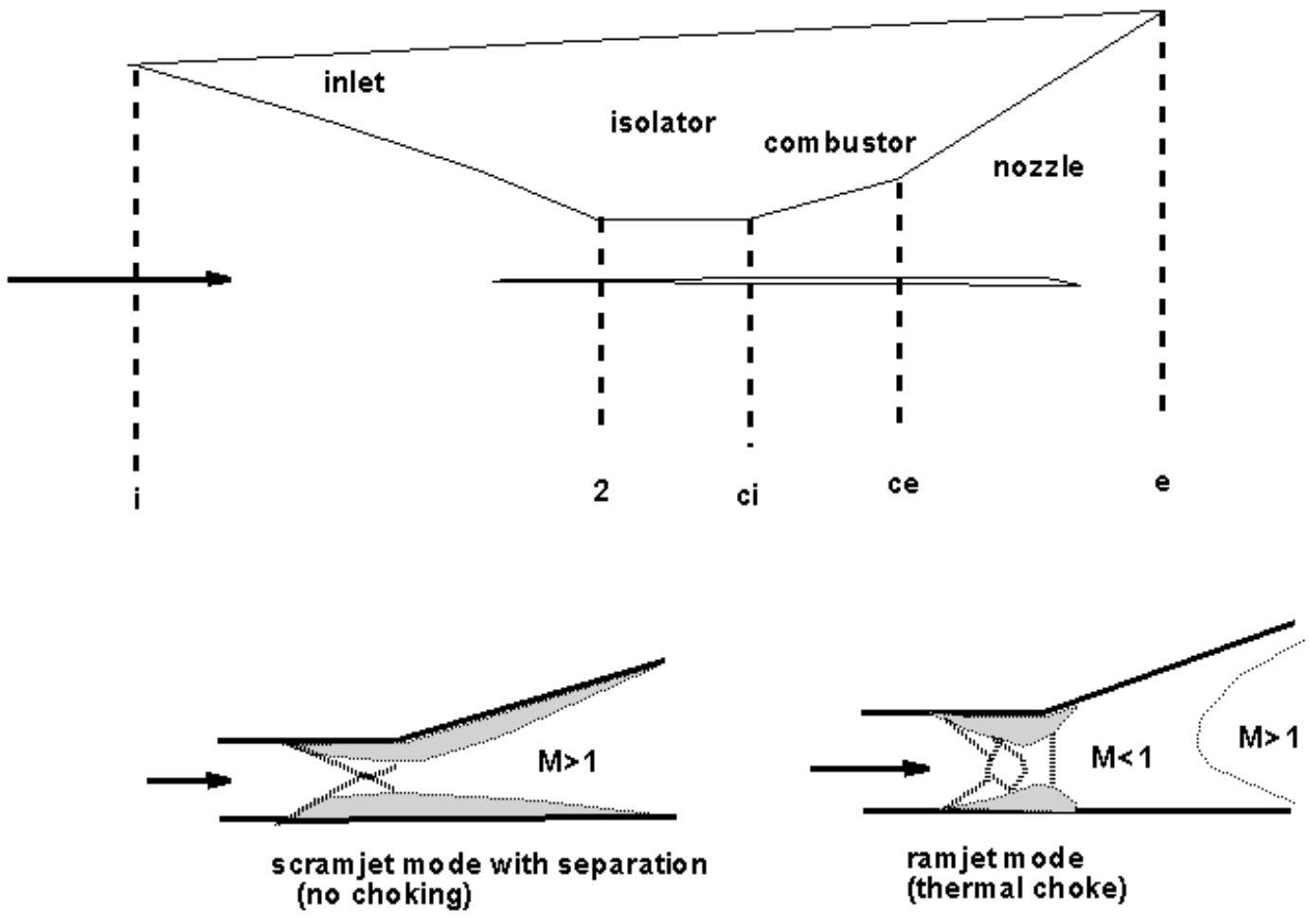

Figure 1. Dual mode scramjet engine indices and mode description

The inlet is assumed to have contraction ratio, $C R$, which is equal to $A_{i} / A_{c i}$. The combustor is assumed to have a linear cross-sectional area distribution with axial location given by $\mathrm{A}_{\mathrm{ce}} / \mathrm{A}_{\mathrm{ci}}$. The nozzle also has a linear crosssectional area distribution, generally different from the combustor area variation. All surfaces of the engine flowpath are considered to be adiabatic for all phases of the work which is focused on providing understanding relevant to the second-law characterization of dual mode operation and operability issues.

\section{Dual Mode Engine Description: Flow-Field and Transition Characterizations}

There are three main modes of dual-mode scramjet operation corresponding to 1) supersonic and unseparated flow throughout the engine from i to e, 2) supersonic core flow with regions of low velocity flow or separated flow extending (usually) upstream into the isolator and downstream into the forward part of the combustor, and 3) ramjet mode in which the flow is essentially attached and subsonic in the main combustor with flow distortion (normal shock train or oblique shock train culminating in a normal shock or compression) in the isolator followed by a thermal throat downstream at some location in the combustor after which the flow returns to the supersonic locus.

As noted in the Introduction and shown in Fig. 1, there are two effects which generally tend to cause a scramjet operating in mode 1) above to switch (or begin to switch) modes. First the adverse pressure gradient which occurs for supersonic heat release without adequate area relief in the combustor can cause mode 2) above to initiate. This adverse pressure gradient tends to cause flow deceleration and possible (likely) separation adjacent to walls which can then propagate upstream into the isolator through the boundary layers on the walls. The flow in the isolator compresses in part through the area constriction associated with the boundary layer and adjacent low speed/separated zones and in part due to the presence of the oblique shock train associated with flow turning over the separated or low speed zones. The core (confined) flow moving into the combustor however remains supersonic, albeit at a lower Mach number and with increased losses upstream in the isolator. In the combustor, the area relief associated with the confined flow as the separated zones close back in to the walls keeps the flow moving 
at supersonic Mach numbers. Usually, if area relief in the combustor is sufficiently designed, a pressure plateau can be observed across the front part of the combustor. (The usual argument is that too much area relief yields a declining pressure trace which indicates inefficient combustion whereas too little area relief can cause an adverse pressure gradient too large for the isolator to handle via isolator distortion effects as described here.) The presence of the distorted flow in the isolator of a supersonic dual-mode system actually is (or can be) a beneficial effect as it gives relief from possible thermal choking as well as less 'Rayleigh' losses downstream in the combustor due to lower Mach number heat addition. One of the goals of the present paper is to explicitly identify the performance/operability/loss characteristics of the dual mode system in terms of these basic entropy/loss and heat drivers.

The second effect which can drive transition (and eventual engine unstart) in a dual mode system is, in fact, thermal choking. If one considers a case in which the pressure gradient associated with combustion is insufficient to cause separation (although the pressure gradient will generally result in lower velocity zones adjacent to the walls upstream of heat addition or combustion), it is obvious that for a given combustor area ratio, $\mathrm{A}_{\mathrm{ce}} / \mathrm{A}_{\mathrm{ci}}$, and isolator inflow Mach number, there will be some critical amount and distribution of heat added (i.e. heat distribution with axial distance) that will cause a supersonic flow to choke. Equivalently, for a given isolator inflow Mach number, $\mathrm{M}_{2}$, and a given heat distribution in the combustor, there is some critical $\mathrm{A}_{\mathrm{ce}} / \mathrm{A}_{\mathrm{ci}}$ which will just cause the supersonic flow to choke, etc. In general, as will be seen with the following analysis, there is a fundamental interplay between energy as heat added to the flow, cumulative irreversibilities (equivalently total pressure ratio) and combustor area relief which determines whether a given flow will choke at a given station. When the flow chokes (in the absence of significant separated flow zones or distortion in the isolator/combustor), upstream interaction of some form will occur. In the absence of an isolator, the inlet/engine will unstart since there is no capability for adjustment of the combustor inflow in terms of either distortion or losses to allow for downstream adjustment to the presence of the thermal choke. If the flow chokes in a constant area combustor in such a case, it will of course choke at the end of the combustor - the constant area combustor can then only operate in ramjet mode with the thermal throat at the end of the combustor and with some distortion (area change and total pressure change) in the isolator such that exactly the right balance between heat release and irreversibilities is exactly maintained. This, of course, is not a stable configuration.

\section{Dual-Mode Engine Description - Analytical Relationships}

The following equations can be readily derived and can be used to determine dual-mode engine performance (and, in fact, the performance of all other ram/scramjet engines). These equations are developed under the simplifying assumptions of perfect gas with constant thermodynamic properties, constant gas constant, definable 'heating equivalent' introduced into the flow, and uniform flow at inflow (i) and at station of interest. Here the equations are written in terms of station 'e'; however, note that they apply at any intermediate station inside the engine as well (i.e. replace ' $e$ ' with ' $x$ '). Usually, of course, one is interested in the values of specific thrust and specific impulse at station e (engine exit plane). However, choking phenomena can occur at combustor locations due to the local cross-sectional area distribution $(\mathrm{A}(\mathrm{x}))$ and heat release distribution $(\mathrm{Q}(\mathrm{x})$ ) (which will drive performance/operability as will be discussed in detail subsequently). Note that the following equations are also exactly valid for multi-dimensional flows as long as the flows at the inlet and exit (or plane of entrance) are undistorted, i.e. uniform. In other words, internal multi-dimensionality is not precluded by the use of these equations. These equations are written in terms of the most fundamental fluid/thermodynamic quantities (heating, irreversibility, and engine area ratio) and provide the foundation for the analytical part of this study of dual mode scramjets.

Equation (1) is the non-dimensionalized specific thrust of the engine (where engine thrust is define as $\dot{m}_{e} U_{e}-\dot{m}_{i} U_{i}+\left(P_{e}-P_{i}\right) A_{e}$, i.e. with the assumption of a constant pressure $P_{i}$ on the outer envelope of the

engine. If net axial force on internal wetted surfaces from $i$ to e is used $\left(\dot{m}_{e} U_{e}-\dot{m}_{i} U_{i}+P_{e} A_{e}-P_{i} A_{i}\right)$ as defined thrust, the area ratio term appearing in the last term in Eq. (1) would be unity.

$$
\frac{\left(\frac{F_{x}}{\dot{m}}\right)}{a_{i}}=M_{i}\left\{(1+f) \frac{U_{e}}{U_{i}}-1+\frac{(1+f)}{\gamma M_{e}{ }^{2}} \frac{U_{e}}{U_{i}}-\frac{1}{\gamma M_{i}{ }^{2}}\left(\frac{A_{e}}{A_{i}}\right)\right\}
$$


The expression for the velocity ratio appearing in Eq. (1) is given as follows:

$$
\frac{U_{e}}{U_{i}}=\frac{M_{e}}{M_{i}} \sqrt{1+\frac{Q}{C_{P} T_{t i}}}\left\{\frac{1+\frac{\gamma-1}{2} M_{i}^{2}}{1+\frac{\gamma-1}{2} M_{e}^{2}}\right\}^{\frac{1}{2}}
$$

Here $\mathrm{Q}$ is defined as heat per mass (inflow) and is non-dimensionalized by the entering total enthalpy per mass. The exit Mach number is found from the following expression:

$$
M_{e}\left(1+\frac{\gamma-1}{2} M_{e}^{2}\right)^{\frac{-(\gamma+1)}{2(\gamma-1)}}=(1+f) \sqrt{1+\frac{Q}{C_{P} T_{t i}}} \frac{A_{i}}{A_{e}} M_{i}\left(1+\frac{\gamma-1}{2} M_{i}^{2}\right)^{\frac{-(\gamma+1)}{2(\gamma-1)}}\left(\frac{P_{t i}}{P_{t e}}\right)
$$

Note that the total pressure recovery $\left(\mathrm{P}_{\mathrm{ti}} / \mathrm{P}_{\mathrm{te}}\right)$ given in Eq. (3) is directly related to the entropy increase associated with irreversibilities between $\mathrm{i}$ and $\mathrm{e}$ as follows:

$$
\frac{P_{t e}}{P_{t i}}=E X P\left\{\frac{-S_{i r r(i \rightarrow e)}}{R}\right\}
$$

It is important to note that $S_{i r r(i \rightarrow e)}$ is defined here as inclusive of all entropy increases which cause a decrease in fluid total pressure. This indicates that entropy increases associated with heat addition, if it occurred at zero Mach number, are treated as inherently 'reversible' in principle and hence do not contribute to $S_{\operatorname{irr}(i \rightarrow e)}$ as defined above. Any additional entropy generated due to finite Mach number heat addition (above that 'reversible' or ideal value) is here treated as inherently internal and hence irreversible since the total pressure is driven down in such a case, as in a convective heat transfer process. This nomenclature is used for simplicity although it is possible, using radiation effects, etc., to imagine energy as heat which was originally transferred by radiation into a flow where $\mathrm{T}<\mathrm{T}_{\mathrm{t}}$ (i.e. into a finite Mach number flow with an attendant total pressure drop) as being removable in a 'reversible' process (and hence the total pressure 'returning' to the original value). This scenario, however, is not of interest in this and related works. Therefore, in this work, the so-called 'Rayleigh' heat transfer losses (total pressure losses and associated entropy gains) are meaningfully assessed as essentially irreversible to an operational jet engine. Nevertheless, a rigorous thermodynamics nomenclature for heat transfer by radiation would properly define the term $S_{i r r(i \rightarrow e)}$ in equation (4) as the entropy increase associated with internal irreversibilities PLUS that portion of the entropy associated with the non-ideal (finite Mach number) energy addition by radiation. The latter term is equal (in terms of a differential heat interaction, $\delta Q$ ) to the following expression: $d S_{\text {non-ideal heat interaction }}=\delta Q\left((1 / T)-\left(1 / T_{t}\right)\right)$.

The non-dimensionalized specific impulse is also defined as follows:

$$
\frac{I_{S P}}{\left(\frac{a_{i}}{g_{0}}\right)}=\left[\frac{\left(\frac{F_{x}}{\dot{m}}\right)}{a_{i}}\right]\left(\frac{1}{f}\right)
$$

These equations yield the powerful observation that the specific thrust and specific impulse of a jet engine (equations written here for a ram/scramjet system, i.e. with no work interaction devices such as compressors or turbines) are simply functions of the following non-dimensional parameters: 


$$
\begin{aligned}
& \frac{\left(\frac{F_{x}}{\dot{m}}\right)}{a_{i}}=\operatorname{funct}_{1}\left(M_{i}, \gamma, \frac{A_{e}}{A_{i}}, \frac{Q}{C_{P} T_{t i}}, S_{i r r(i \rightarrow e)}\right) \\
& \frac{I_{S P}}{\left(\frac{a_{i}}{g_{0}}\right)}=\text { funct }_{2}\left(M_{i}, \gamma, \frac{A_{e}}{A_{i}}, \frac{Q}{C_{P} T_{t i}}, S_{i r r(i \rightarrow e)}\right)
\end{aligned}
$$

If desired, these functional relationships can be appropriately rewritten with the non-dimensional heating term $\frac{Q}{C_{P} T_{t i}}$ replaced by $\frac{Q}{C_{P} T_{i}}$ in order to remove the flight Mach number dependence of the heating term such that the parameters are explicitly independent.

\section{Analytical Treatment of the Dual-Mode Problem with Entropy Considerations}

This section discusses results obtained by applying the relationships given in the previous section to the dualmode scramjet engine regime. Of particular interest is the role of entropy and heat release (as well as area ratio and isolator) on choking phenomena, operability, and engine performance. Note that isolator length is not an explicit parameter here; as will be seen, thermal choking and (eventual) engine unstart are driven by the degree which a given isolator can sustain distortion (resulting in lower Mach number or subsonic isolator exit flow) and the total pressure losses (entropy increases associated with irreversibility) associated with that distortion. If an isolator cannot sustain a required degree of distortion without too much irreversibility (in order to ensure started engine operation), it will disgorge and the engine will unstart, regardless of the length of the isolator. If, on the other hand, the isolator is too short, it will also disgorge, even before the fundamental choking and irreversibility limits causing engine unstart discussed in this work occur. Therefore, all subsequent discussion is predicated on the assumption that the isolator length is adequate to provide the required distortion and associated losses for examples given.

Figure 2 provides the family of contour lines of specific thrust (non-dimensionalized as given in the above equations) cross-plotted versus irreversibility, $S_{i r r} / R$ (y axis) and heating value, $Q / C_{p} T_{t i}$ (x axis). This is done for a flight Mach of 6 and overall engine area ratio of $A_{e} / A_{i}=1.0$. Note the 'overall choking limit' of the engine which naturally emerges from these contours. This upper limit (or line) implies that the Mach number at engine exit becomes 1.0 at a given heat value and the associated indicated irreversibility. If the engine suffers overall irreversibility $\left(\mathrm{S}_{\mathrm{irr}} / \mathrm{R}\right.$ ) greater than this maximum amount (at that given $\mathrm{Q} / \mathrm{C}_{\mathrm{p}} \mathrm{T}_{\mathrm{ti}}$ ), the engine will unstart. Flow conditions below this line indicate possible started engine configurations (not necessarily so, however, since engine internal cross-sectional areas will be constricted inside the engine flowpath with possible choking/unstart originating from inside the engine). Note that in Fig. 2 that maximum specific thrust occurs at maximum heat and minimum irreversibility. Also note that at high overall irreversibilities (as will inevitably occur for scramjets), purposely obtaining large increases in released heat (i.e. seeking mixing enhancement in realistic scramjets) with even relatively small or modest associated irreversibility increases are not necessarily beneficial from the standpoint of producing increased thrust. This observation is also true if contours of specific impulse are examined in like manner. This of course indicates that it is always unwise to seek $100 \%$ mixing (and combustion) and that the efficacy and evaluation of the usefulness of mixing enhancement is directly dependent upon the overall irreversibility that the entire engine sustains. 


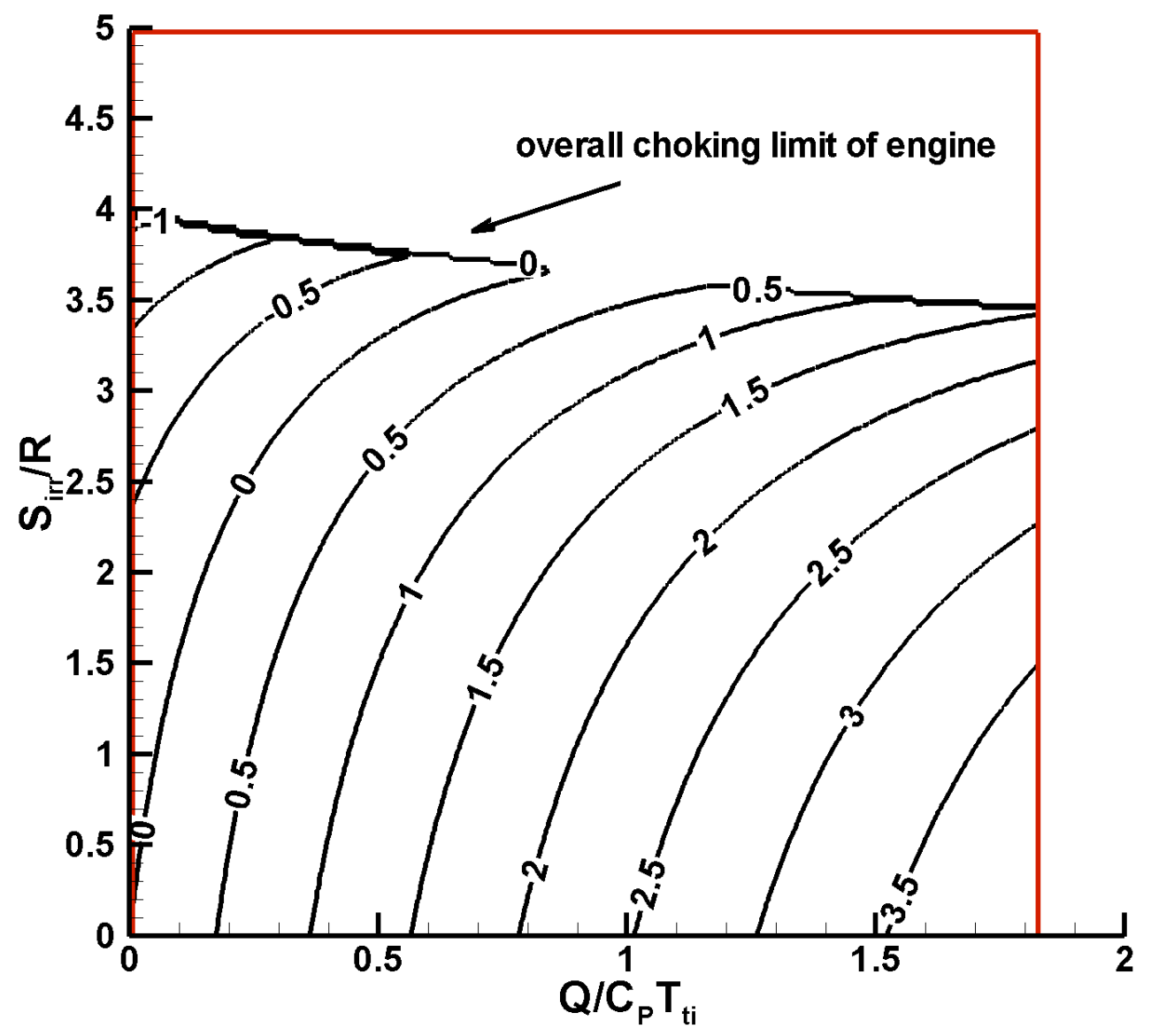

Figure 2. Contours of engine specific thrust (non-dimensionalized) on irreversible entropy heat diagram (flight Mach 6, $\left.A_{\mathrm{e}} / \mathbf{A}_{\mathrm{i}}=\mathbf{1 . 0}\right)$

Figure 3 is a plot of choking limits in a given engine configuration using Eq. (3) in the previous section. Here, the flight Mach number is 6.0 and inlet CR is 5.0. In order to develop these choking limits, a cumulative heat release distribution schedule has been defined. This distribution is based on cumulative energy per mass released, $Q(x)$ determined by a power law relationship using the non-dimensional length along the combustor, i.e.

$$
Q(x)=Q_{\max }\left(\frac{x}{L_{c}}\right)^{\frac{1}{3}}
$$

Here $Q_{\max }$ is simply $f H_{\text {prop }}$ where $f$ is the stochimetric fuel-ratio for $\mathrm{H}_{2}-$ air combustion $(f=0.029)$ and $H_{\text {prop }}$ is the heating value for $\mathrm{H}_{2}$ in air $\left(1.2 \times 10^{8} \mathrm{~J} / \mathrm{kg}\left(\mathrm{H}_{2}\right)\right)$. In order to generate the choking limits in this plot, Eq. (3) is applied with $\mathrm{M}(\mathrm{x})=1.0$ (recall that the relationships in the previous section can be evaluated at any point along the engine flowpath - i.e. replace the subscript ' $\mathrm{e}$ ' with the local ' $\mathrm{x}$ '). Also, recall that engine cross-sectional area is assumed to vary linearly with $\mathrm{x}$ station from combustor entrance (ci) to combustor exit (ce) so that each $\mathrm{Q} / \mathrm{C}_{\mathrm{p}} \mathrm{T}_{\mathrm{ti}}$ corresponds to a given area (ratio) that the local flow experiences. For any given overall area ratio of the combustor $\left(\mathrm{A}_{\mathrm{ce}} / \mathrm{A}_{\mathrm{ci}}\right)$ there is then a given $\mathrm{S}_{\mathrm{irr}} / \mathrm{R}$ that will cause the local flow at that $\mathrm{Q} / \mathrm{C}_{\mathrm{p}} \mathrm{T}_{\mathrm{ti}}$ to choke. Note the relief from choking obtained at larger combustor area ratios $\left(A_{c e} / A_{c i}\right)$. Significantly, this plot can also be superimposed on the plots of specific thrust (or specific impulse) for a given overall exit to inlet area ratio $\left(\mathrm{A}_{\mathrm{e}} / \mathrm{A}_{\mathrm{i}}\right)$ as shown previously. Note that for the case in which heat addition is completely ended by nozzle inflow, the 'allowable' choking limit (i.e. a given choking limit line shown in Fig. 3) could be shown as simply continuing upward in a vertical line (from the end of the line on Fig. 3) to the maximum (overall) engine choking limit as shown in Fig. 2 (since some irreversibilities would occur in the nozzle, presumably). Keep in mind that this plot is NOT a plot of the 'trajectory' 
(history) of an actual fluid dynamic process from inlet to exit in an engine; it simply represents overall choking limits which may or may not occur for any flow within the combustor.

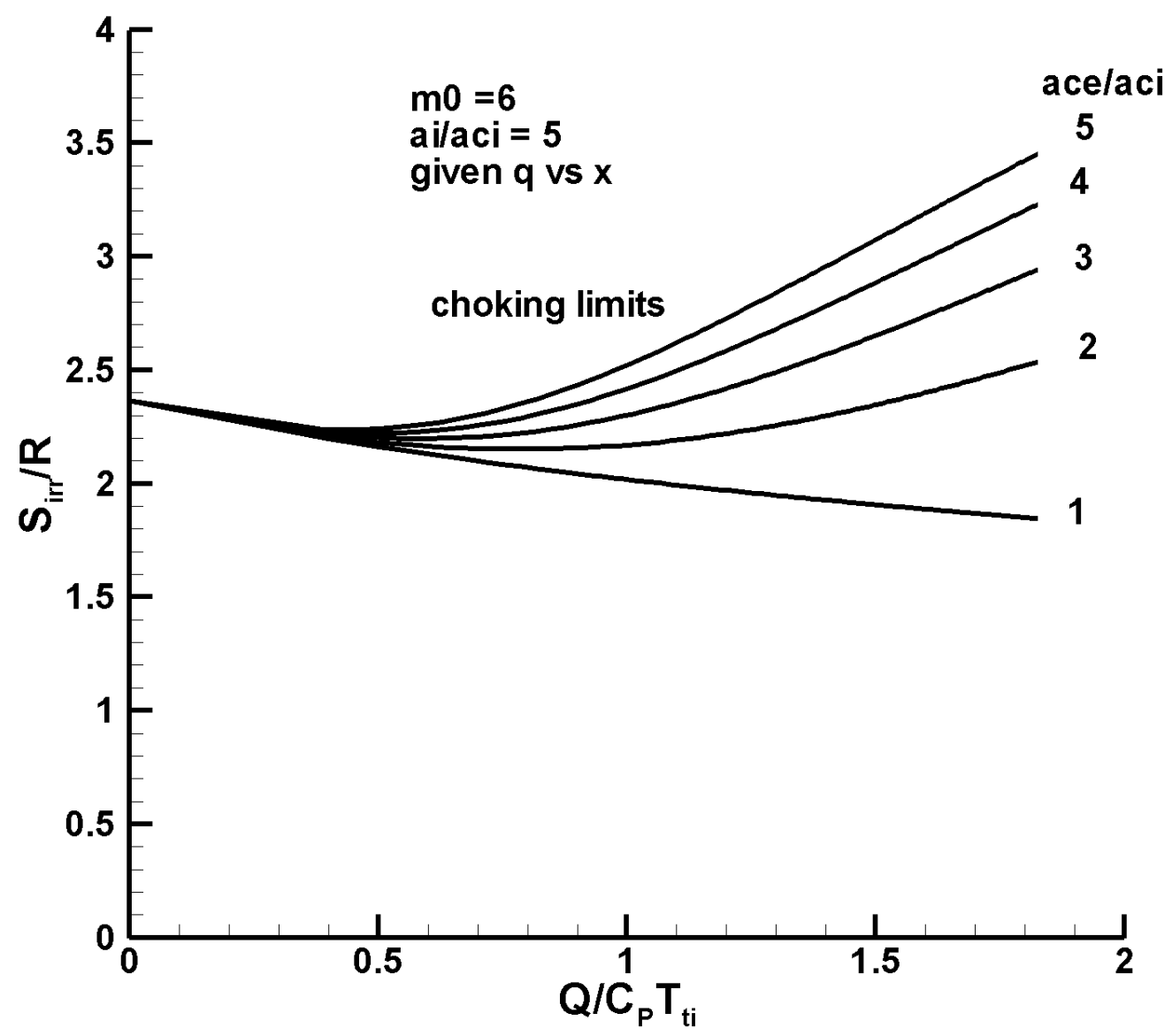

Figure 3. Engine choking limits for given area ratios (flight Mach 6)

Figure 4 is a comparative plot of engine choking limits for flight Mach numbers of 5, 6, and 7. Here the same $\mathrm{A}_{\mathrm{i}} / \mathrm{A}_{\mathrm{ci}}$ of 5.0 and heating distribution in the combustor as used for Fig. 3 is used for all three flight Mach numbers. However, note that rather than the denominator of the non-dimensional heating value being based on $T_{t i}$ (as for most results presented in this work which are given at fixed Mach number), the ambient temperature, $T_{i}$ is used in this particular plot. This is done in order to remove the Mach number dependence from the $\mathrm{x}$ axis variable (the heating term). In Fig. 4, choking limits can be seen to be relaxed (i.e. irreversibilities necessary for choking to occur increase) with increasing flight Mach number; this is fortunate since irreversibilities will themselves inevitable increase for increased flight Mach number. However, the choking limits generally relax more quickly than irreversibilities mount (as flight Mach number increases) such that two effects occur: 1) dual-mode (choking limit driven) operation is precluded for flight Mach numbers above 7.0 for reasonable contraction and area ratios through the engine and 2) the use of higher contraction ratios is possible/preferred/necessary at higher flight Mach numbers, which also tends to reduce losses (irreversibilities) otherwise incurred as well as facilitating faster fuel/air mixing and hence combustion. 


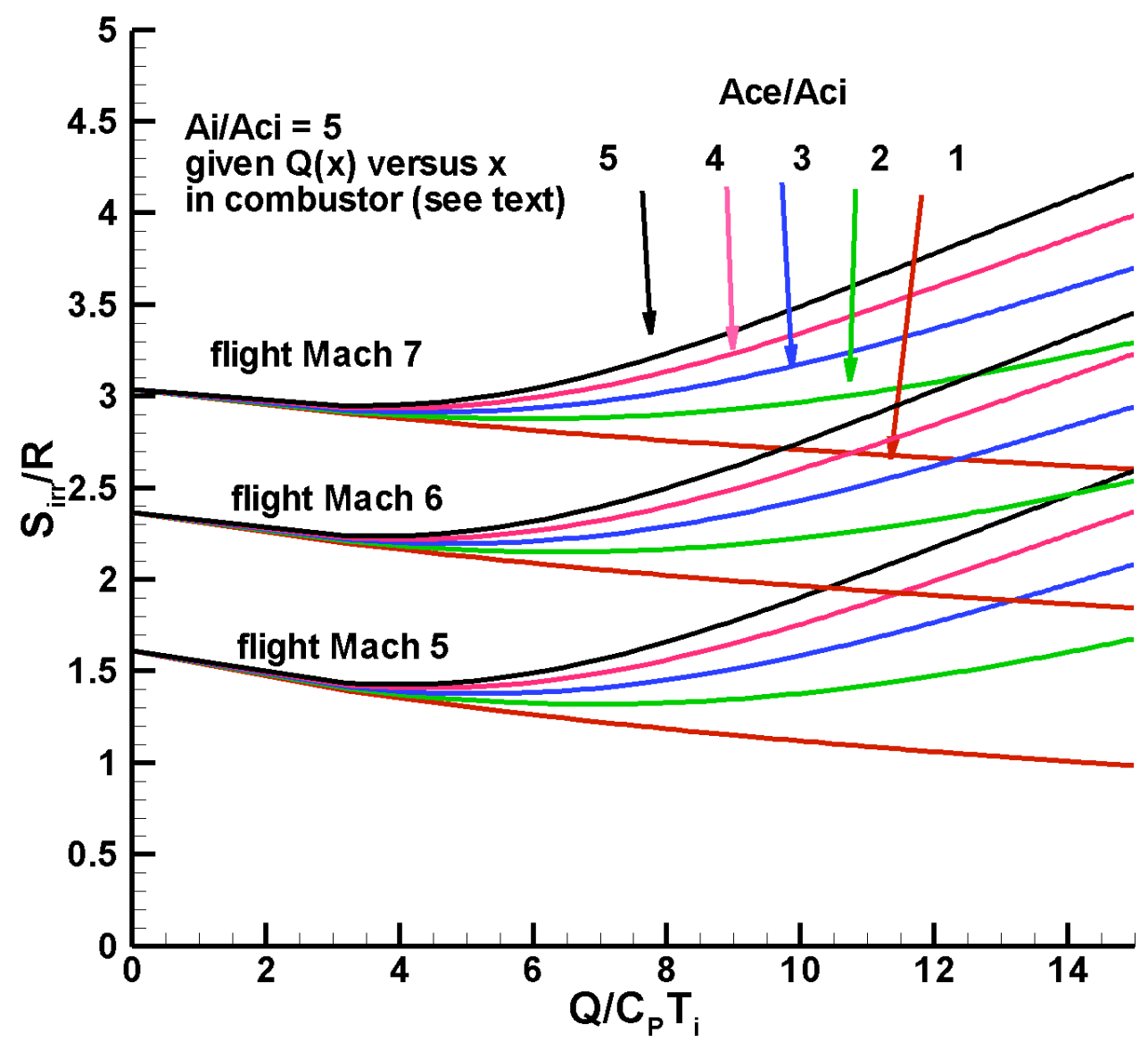

Figure 4. Engine choking limits for given area ratios (flight Mach 6, 7, and 8)

Figure 5 is a plot where an 'actual' or 'example' specific fluid dynamic process is plotted on a $S_{\text {irr }} / R$ (irreversibility) versus $\mathrm{Q} / \mathrm{C}_{\mathrm{p}} \mathrm{T}_{\mathrm{ti}}$ (heat) plot using calorically perfect quasi-one-dimensional equations without friction or distortion (but with fluid dynamic area constriction) and marching in space in order to develop the solution 'trajectory' through the combustor. For this case, the freestream Mach number is 7.0, the inlet contraction ratio is 5.0, and a total pressure recovery of 0.2 in the inlet is used which then gives the $S_{\text {irr }} / R$ initial of 1.6 (as shown in Fig. 5 ) at the entrance to isolator. There is a specific isolator entrance Mach number, $M_{2}$, corresponding to this total pressure recovery and inlet contraction ratio $\left(\mathrm{A}_{\mathrm{i}} / \mathrm{A}_{\mathrm{ci}}\right)$; this $\mathrm{M}_{2}$ is found through application of Eq. (3). The red line beginning at the $S_{\text {irr }} / R$ of 1.6 (zero heat value) is then a Rayleigh heating process or 'heating line' $\left(A_{c e} / A_{c i}=1\right)$ from the combustor entrance (isolator has no losses considered yet, hence $\mathrm{M}_{\mathrm{ci}}=\mathrm{M}_{2}$ ) with calculations performed on the supersonic locus. Subsequent calculations for non-unity $A_{c e} / A_{c i}$ of 2 and 3 lie very close to the $A_{c e} / A_{c i}=1$ results and hence are difficult to distinguish in terms of observed $S_{i r r} / R$ versus $Q / C_{p} T_{t i}$ on the heating line (i.e. there are actually three heating lines lying very close together in this plot). However, the higher $\mathrm{A}_{\mathrm{ce}} / \mathrm{A}_{\mathrm{ci}}$ heating lines lie slightly higher than the Rayleigh case $\left(\mathrm{A}_{\mathrm{ce}} / \mathrm{A}_{\mathrm{ci}}=1.0\right)$. For the case of the $\mathrm{A}_{\mathrm{ce}} / \mathrm{A}_{\mathrm{ci}}=1.0$ heating process, the heating line intersects the relevant choking limit line for $A_{c e} / A_{c i}=1.0$ at a heat value $\left(Q / C_{p} T_{t i}\right)$ of around 0.52. In other words, for that case, the supersonic flow chokes with the result that something will happen - or adjust - upstream. Note that the $\mathrm{A}_{\mathrm{ce}} / \mathrm{A}_{\mathrm{ci}}=2$ line also intersects its own choking limit line (albeit at a slightly higher allowable heating value.) The $\mathrm{A}_{\mathrm{ce}} / \mathrm{A}_{\mathrm{ci}}=3$ line, however, just 'clears' the $\mathrm{A}_{\mathrm{ce}} / \mathrm{A}_{\mathrm{ci}}=3$ choking limit line indicating that a combustor expansion ratio of around 3 would ensure supersonic flow throughout the combustor/engine (i.e. maintain scramjet mode within the dual-mode system with no need of isolator distortion).

Also plotted on Fig. 5 are two subsonic heating lines with the lower line (initiating at the $S_{\text {irr }} / R$ of 1.6 ) corresponding to subsonic flow at combustor entrance assuming isentropic deceleration to subsonic Mach from the given isolator entrance Mach of 2 (as if the flow moved through an effective throat in the isolator - presumably a distortion-induced throat but without any total pressure losses - i.e. no entropy increase associated with isolator 
distortion/diffusion). There is no thermal throat for this case (i.e. the flow process does not intersect the choking limit line so it would never go supersonic downstream of combustor hence the engine is not working in ramjet mode). The higher subsonic heating line which initiates at the $S_{\text {irr }} / R$ of 2.3 utilizes an overall inlet/isolator total pressure ratio of 0.1 (i.e. this case is based on prescribed additional loss in the isolator - recall inlet loss is fixed at a total pressure ratio of 0.2 for started flow). This line also exhibits no thermal throat in the combustor; hence will not return to the supersonic locus downstream of combustor exit. Note that a subsonic solution achieved by passing the flow which enters the isolator through a normal shock yields an initial $\mathrm{S}_{\text {irr }} / \mathrm{R}$ of about 2.65 - if the heating line were computed from that condition using subsonic heat addition, it would obviously intersect the $A_{c e} / A_{c i}=1$ line (i.e. the flow would choke and unstart the engine). If, however, $\mathrm{A}_{\mathrm{ce}} / \mathrm{A}_{\mathrm{ci}}>1$, the resulting subsonic heating line might have a thermal throat on the relevant choke limit line (just achieving tangency to the choke limit line) thus enabling supersonic flow downstream (i.e. such that the dual-mode system is in the ramjet mode). Finally, there would be a reduced initial loss $S_{\text {irr }} / R$ (reduced from the normal shock limit at $M_{2}$ ) corresponding to $A_{c e} / A_{c i}=1$ which would just give a thermal throat at combustor exit, with subsequent supersonic flow in the nozzle.

Also superimposed on Fig. 5 are specific impulse lines for overall engine expansion ratio $A_{e} / A_{i}=1.0$ at flight Mach 7. Note that if the nozzle was completely isentropic, the engine specific impulse would simply be usefully identified as the contour value where the heating line ended on this plot since there is no further irreversibility (or heat) in the nozzle.

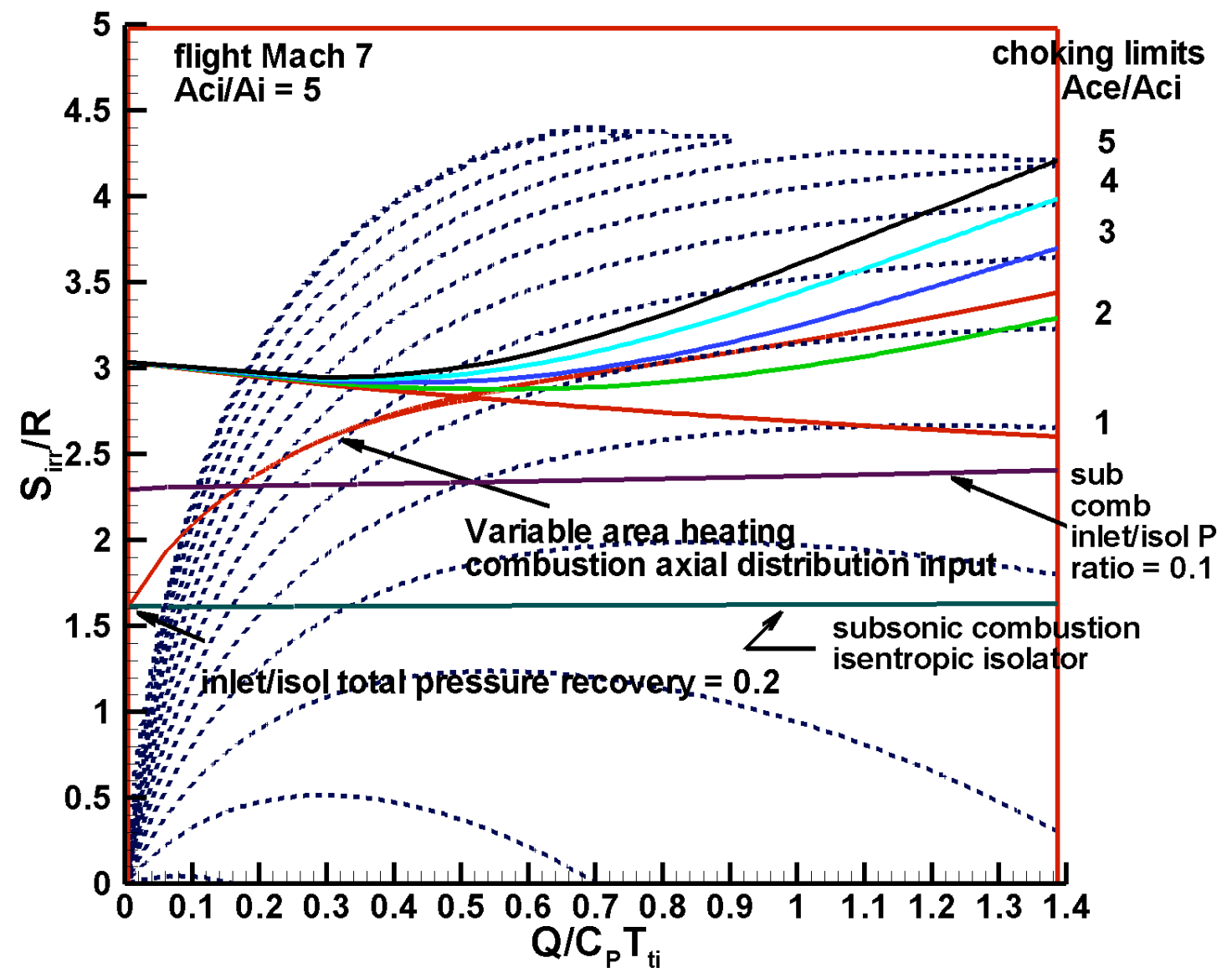

Figure 5. Heating versus irreversibility for Mach 7 combustor showing heating line and choking limits with contours of $I_{\text {sp }}$ superimposed

Figure 6 is a plot of $\mathrm{Q} / \mathrm{C}_{\mathrm{p}} \mathrm{T}_{\mathrm{ti}}$ versus $\mathrm{S}_{\mathrm{irr}} / \mathrm{R}$ for a case of supersonic dual mode operation with a separated flow model (modeled simply in terms of constricted effective area ratios) through the isolator/combustor. The combustor is a constant area duct, i.e. baseline or nominal flow corresponds to Rayleigh flow. The case corresponds to flight Mach 7 and an assumed inlet total pressure recovery of 0.6 with an axial heating distribution taken as that suggested 
by Heiser and Pratt using $\theta=2$. Results are for $A_{c e} / A_{i}=0.2$, i.e. the nominal $A_{c i}=A_{2}=A_{e}$. Shown on this plot are three different 'families' of choking limits $\left(\mathrm{A}_{\text {ce }} / \mathrm{A}_{\text {cieff }}\right)$. $\mathrm{A}_{\text {cieff }}$ corresponds to the flow core cross-sectional area at combustor entrance/isolator exit. In other words, the effective core area for the fluid as it passes over the separated/low velocity regions in the isolator/combustor will be the relevant area for fluid dynamic computations. Hence the choked flow limits are presented for three cases; $0 \%$ blockage $\left(\mathrm{A}_{\text {cieff }}=\mathrm{A}_{\text {ciactual }}\right), 67 \%$ blockage $\left(\mathrm{A}_{\text {cieff }}=0.333 \mathrm{~A}_{\text {ciactual }}\right)$, and $75 \%$ blockage $\left(\mathrm{A}_{\text {cieff }}=0.25 \mathrm{~A}_{\text {ciactual }}\right)$. This will mean that one must compute/analyze the heating line for a given situation using this 'additional' or effective area compression, with similar observations (except for a given effective area scenario) as discussed in Fig. 4. As a very simple model in this study for heating line computations, the effective area in the combustor is assumed to decrease linearly to $\mathrm{A}_{\mathrm{ce}}$ (i.e. no separation at $A_{\text {ce }}$ ) from the value at $A_{\text {ci }}$.

As can be seen in Fig. 6, the flow chokes for $0 \%$ blockage at a heat value around 0.7. (If the combustor had area relief such that $\mathrm{A}_{\mathrm{ce}} / \mathrm{A}_{\mathrm{ci}}=$ about 1.5 , it would not choke). The flow also cannot maintain supersonic flow for a case of $50 \%$ blockage - i.e. it chokes as well (like the $0 \%$ blockage case) no matter what (reasonable) initial losses at combustor entrance are assumed. The $50 \%$ blockage case is therefore not shown. For the case of $67 \%$ blockage, the heating line through the combustor can be found (as shown) that just gives (touches) Mach 1.0 on the relevant $\mathrm{A}_{\mathrm{ce}} / \mathrm{A}_{\text {cieff }}$ choking limit line for that amount of blockage (i.e. it is tangent to that line). This line is found assuming the indicated initial $S_{\text {irr }} / R$ (slightly larger than that associated with the $S_{\text {irr }} / R$ of 0.5 for the base-line inlet total pressure ratio of 0.6); physically this implies some degree of isolator distortion losses associated with the low velocity/separated zones that give this total pressure ratio (and resulting combustor entrance $S_{\text {irr }} / R$ ) upstream of combustion. One can also postulate that supersonic-throughout flow will exist for this given distribution for initial losses less than shown plotted (i.e. lines that totally 'clear' the choking limit line exist) - provided that the given distortion (i.e. blockage) can exist in the isolator with those smaller losses. A third heating line is shown corresponding to $75 \%$ blockage such that it also just touches (is tangent to) the associated choking limit line (for $75 \%$ blockage). Similar comments can be made here as for the previous $67 \%$ blockage case. Note the higher initial irreversibility demanded for this line - corresponding to more blockage and higher irreversibility in the isolator.

This plot and associated discussion mainly investigate the choking limits for supersonic (scramjet) mode operation of a dual-mode system and do not directly address the driver on the formation of the low velocity/separated zones to begin with - the adverse pressure gradient issue which can cause the separated zone formation (and an effective area ratio distribution and loss history) before choking even becomes an issue. Obviously, however, this sort of phenomena and results shown here (build-up of separated or low-speed zones and changes in loss history and heating line trajectories seen) will apply as well to unchoked supersonic flows which are experiencing a sufficiently large adverse pressure gradient. 


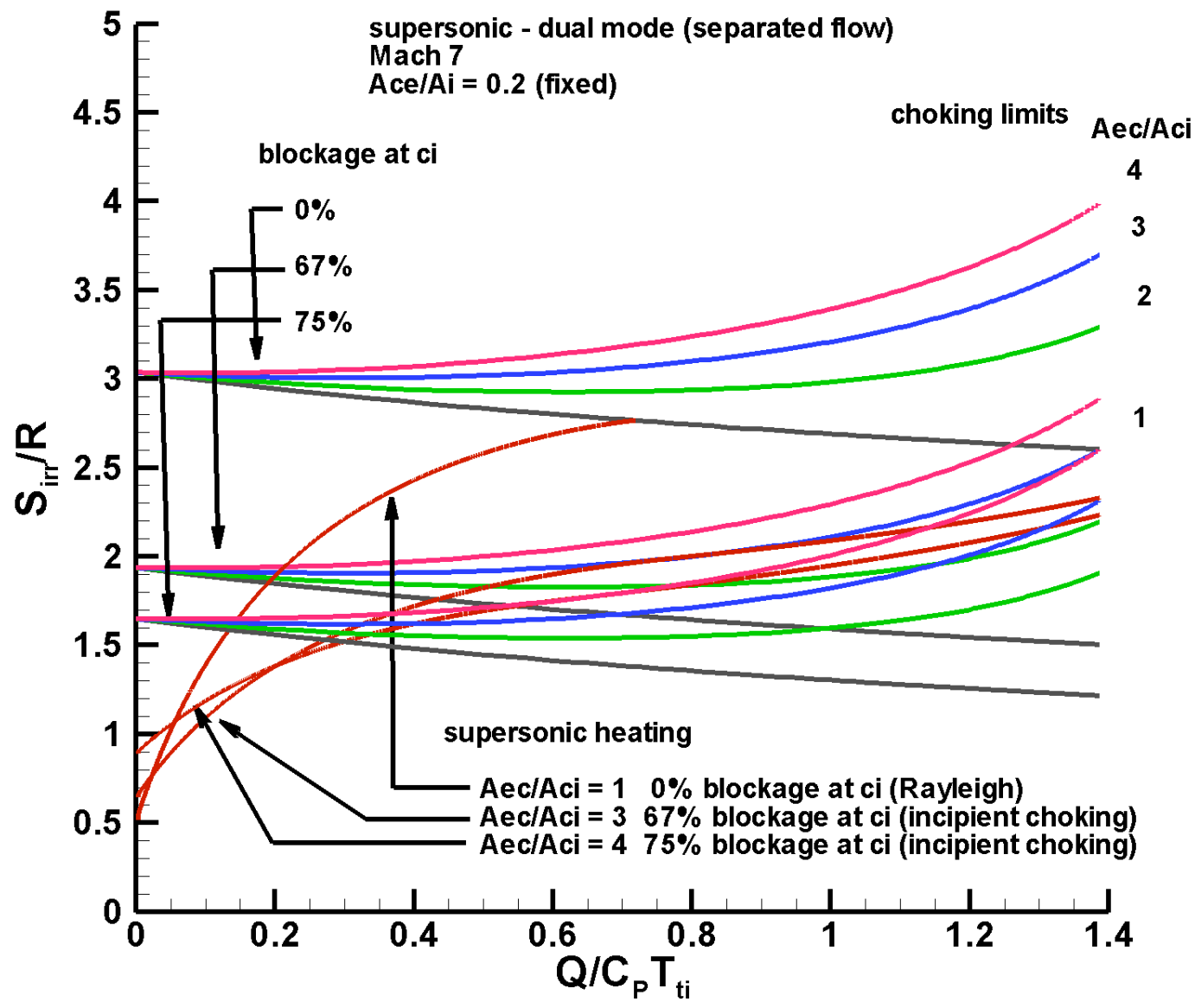

Figure 6. Heating versus irreversibilility for supersonic-dual mode (with separated flow) engine operation flight Mach 7, with various blockages at isolator exit

Figure 7 is simply a detail of the region in Fig. 6 where the indicated supersonic and distorted flow heating lines 'touch' their respective choking limit lines to indicate the formation of thermal throats; for flows beyond these limits there would be either engine unstart or transition to ramjet operation (subsonic flow) of the dual-mode system, depending on the capabilities of the isolator. 


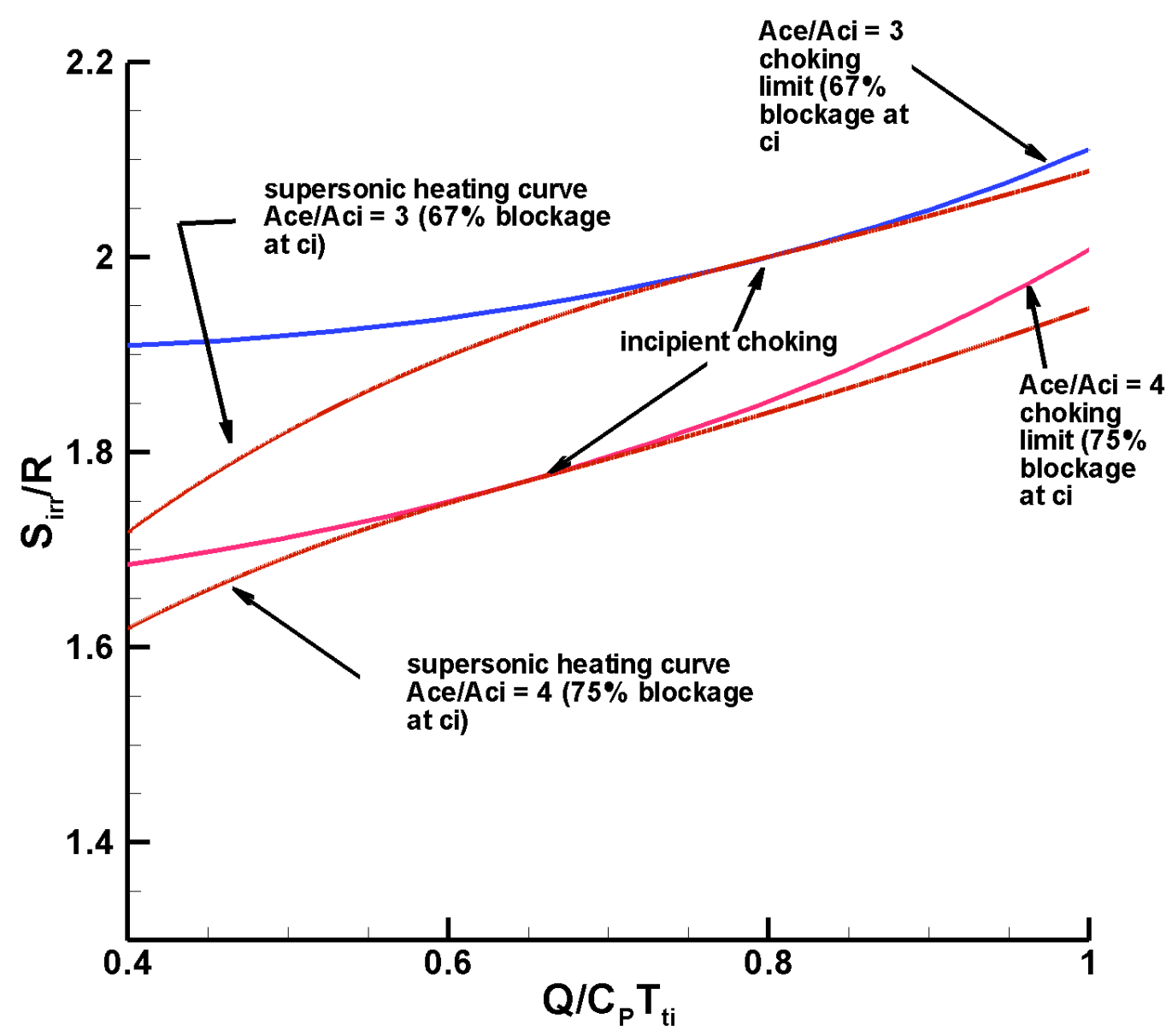

Figure 7. Detail of Fig.6 showing incipient choking for blockage cases

Figure 8 is a compilation of results relevant to a case similar to that reported in Heiser and Pratt in which a Mach 1.5 isolator inflow is assumed with a given (fixed) heating distribution (see Heiser and Pratt ) with $\theta=2$. Here, the combustor area ratio is varied $\left(\mathrm{A}_{\mathrm{ce}} / \mathrm{A}_{\mathrm{ci}}\right.$ varied) and the effects of that parameter on the flow are examined. Plotted in Fig. 8 is the $\mathrm{A}_{\mathrm{ce}} / \mathrm{A}_{\mathrm{ci}}$ combustor choking limits for six different area ratios as shown. Note that two supersonic heating lines are also shown. They (the supersonic heating lines) begin with the indicated (initial) $\mathrm{S}_{\text {irr }} / \mathrm{R}$ corresponding to an isolator entrance Mach number, $\mathrm{M}_{2}=1.5$ and an $\mathrm{A}_{\mathrm{i}} / \mathrm{A}_{\mathrm{ci}}$ of 5 (flight Mach number of 5.0 is assumed for these results). Pressure gradients in the flow do not reach values that would trigger separation for supersonic flow; hence no separated models are examined. The two supersonic heating lines correspond to an $\mathrm{A}_{\mathrm{ce}} / \mathrm{A}_{\mathrm{ci}}$ of 1.8 and an $\mathrm{A}_{\mathrm{ce}} / \mathrm{A}_{\mathrm{ci}}$ of 1.4617. Note that the case with $\mathrm{A}_{\mathrm{ce}} / \mathrm{A}_{\mathrm{ci}}$ of 1.8 easily remains supersonic - it does not even approach the choking limit line. When the area ratio of the combustor is reduced to 1.4617 as shown, the supersonic flow heating line for that case just intersects that line, hence representing a thermal choke point in supersonic flow. Obviously, the engine will not/ cannot operate in scramjet mode for any area ratio less than this value. The relevant questions are then these: Can the combustor operate at lower area ratios if it transitions to ramjet mode and, if so, what are those limits?

Plotted in Fig. 8 are four lines corresponding to subsonic combustion throughout the entire combustor. Each of these heating lines begins at a different $\mathrm{S}_{\text {irr }} / \mathrm{R}$ initial (combustor entrance/isolator exit) with the highest initial value $\left(\mathrm{S}_{\text {irr }} / \mathrm{R}\right.$ approximately 1.52 ) corresponding to a normal shock at the $\mathrm{M}_{2}=1.5$ (unstart limit). For this case, there is an allowable combustor area ratio $\left(\mathrm{A}_{\mathrm{ce}} / \mathrm{A}_{\mathrm{ci}}\right)$ that just reaches thermal choking as shown $\left(\mathrm{A}_{\mathrm{ce}} / \mathrm{A}_{\mathrm{ci}}=1.301\right)$. Beyond the $\mathrm{Q} / \mathrm{C}_{\mathrm{p}} \mathrm{T}_{\mathrm{ti}}$ at which this thermal choke point occurs, the flow is supersonic and expanding (locus not shown here) on the $\mathrm{A}_{\mathrm{ce}} / \mathrm{A}_{\mathrm{ci}}$ heating line. That this happens (supersonic flow downstream of the choke point) can be proved either by 
examining the derivative of $\mathrm{dM} / \mathrm{dx}$ for the given heating distribution and area ratio of combustor or by actually computing supersonic flow from the choked flow point downstream to combustor exit. In any event, it is clear that there is single choke point (i.e. $\mathrm{A}_{\mathrm{ce}} / \mathrm{A}_{\mathrm{ci}}$ ) allowable for that upstream (isolator) loss history corresponding to a normal shock at $\mathrm{M}_{2}=1.5$. Note that there is no solution possible (at least without supersonic distortion as discussed earlier) for area ratios between 1.4617 and 1.301 since the ramjet mode cannot be used (it would require an initial irreversibility larger than that allowed for isolator unstart - i.e. associated with a normal shock at $\mathrm{M}_{2}=1.5$ ). For area ratios less than 1.301, there is a possible range of ramjet mode operation as shown (ranging down to $\mathrm{A}_{\mathrm{ce}} / \mathrm{A}_{\mathrm{ci}}=$ 1.239). These would require progressively less irreversibility in the isolator, which may or may not be sustainable (since that would occur via flow distortion/normal shock trains). In any event, below an $A_{c e} / A_{c i}$ of 1.239 , the thermal throat passes downstream (out) of the combustor and hence the engine cannot operate in the ramjet mode.

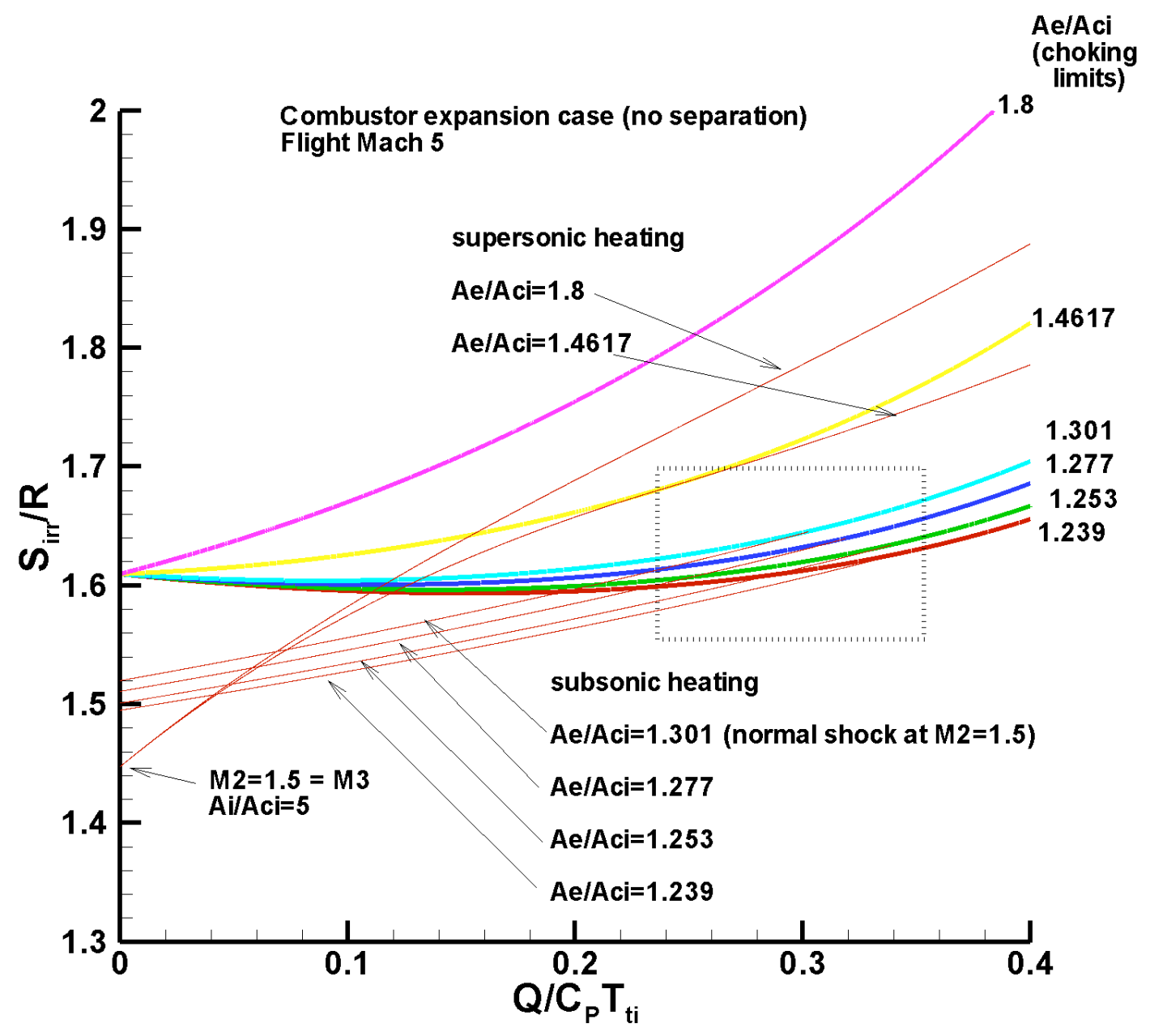

Figure 8. Flight Mach 5 engine with ramjet mode shown (combustor area variation study)

A detail of this figure is seen in Fig. 9 which shows the region where the ramjet mode throats exist for these area ratios $\left(\mathrm{A}_{\mathrm{ce}} / \mathrm{A}_{\mathrm{ci}}\right)$. Note that beyond the thermal throat in all cases, the flow is on the supersonic locus. 


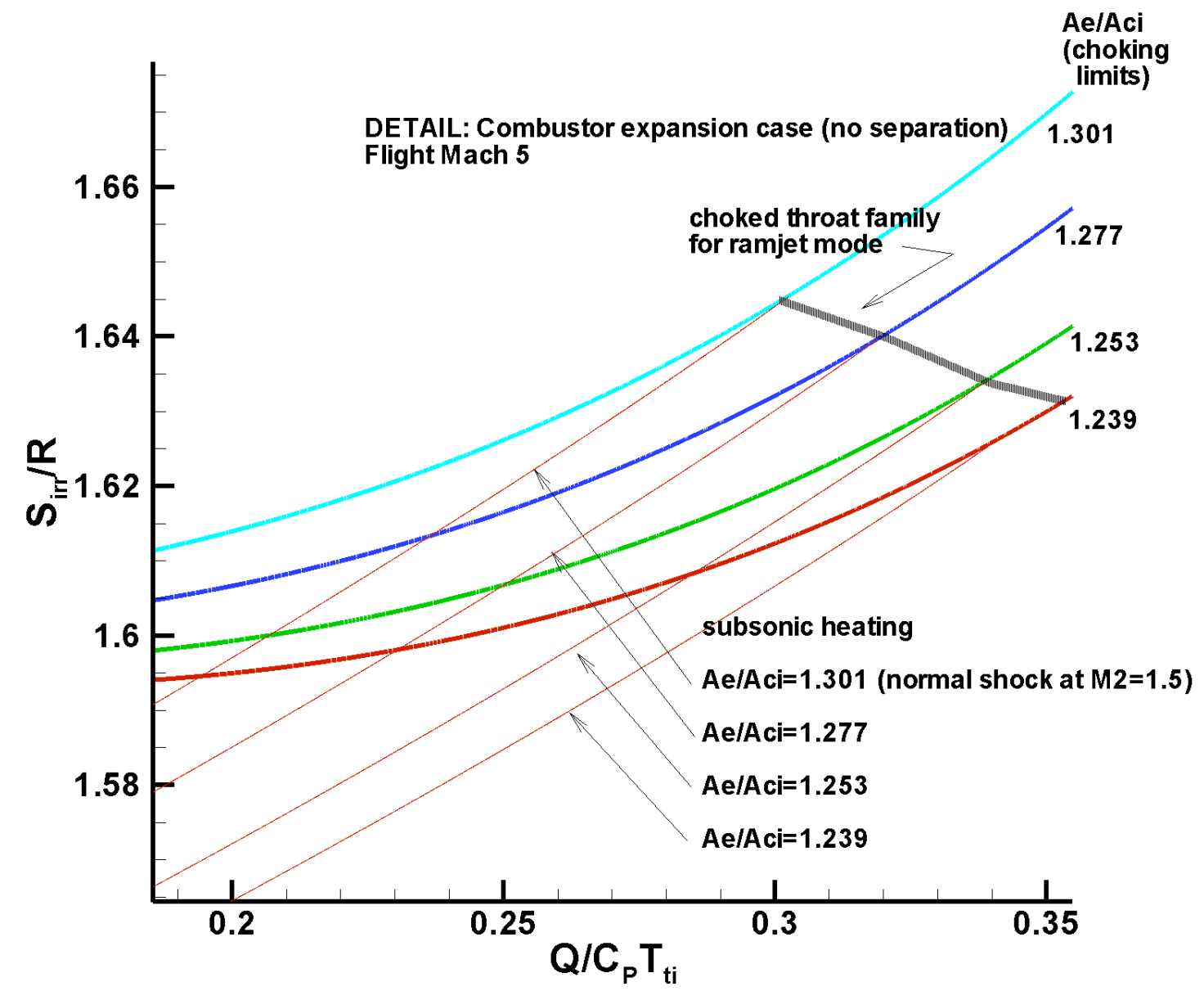

Figure 9. Detail of Fig. 8 showing choke points for ramjet mode operation

\section{Description of VULCAN CFD Code}

The CFD code used for all simulations in the following sections was VULCAN version 5.0.0, developed at NASA Langley. This CFD tool solves the full, viscous Navier-Stokes equations, and here uses a standard k-omega turbulence model with the Menter Shear Stress Transport model modification. Triple interval curve fits which are valid through $20,000 \mathrm{~K}$ are used for thermodynamics. Since the configurations modeled here used simple energy addition as a model for exothermic heat release associated with fuel addition, no fuel-air finite rate chemical kinetics model was used in this study.

\section{Description/Overview of 2-D Parametric Study Utilizing CFD: Simplified Heating (Heating Blocks)}

The following two sections overview a parametric CFD study undertaken to provide both a numerical data base for the second-law analysis of the dual-mode problem and a direct comparison with the analytical results discussed in previous sections. In order to reduce the complex dual mode problem to its essential elements of interest for this basic study, the following assumptions were used in the CFD analysis:

1) A symmetric two-dimensional configuration was defined encompassing a reference isolator, combustor, and nozzle section at $30 \mathrm{~km}$ altitude with fixed isolator length and height, combustor and nozzle expansion angles, free-stream flight Mach number of 6.0 and isolator entrance Mach number of 2.0. See Fig. 10 for a sketch of the 2-D geometry modeled. The isolator was made very long in order to eliminate isolator length as an explicit issue in causing engine unstarts since this study was primarily interested in choking limits; 
however isolator losses were relatively large due to isolator length which implicitly affects thermal choking.

2) The flow conditions at isolator entrance (station 2) were backed out from the Mach 2.0 isolator entrance requirement and an assumed inlet total pressure recovery of 0.2 (i.e. the inlet was not computed using CFD) such that $\mathrm{P}_{\mathrm{t} 2} / \mathrm{P}_{\mathrm{ti}}=0.2$. This results in a required inlet contraction ratio of $6.31\left(\mathrm{~A}_{\mathrm{i}} / \mathrm{A}_{2}=\mathrm{A}_{\mathrm{i}} / \mathrm{A}_{\mathrm{ci}}=6.31\right)$

3) In this part of the study, heat release within the combustor was directly simulated using the available heat deposition capability existent in the CFD code, i.e. fuel injection effects and reaction (with subsequent changes in molecular weight, etc.) were eliminated as variables in order to provide direct comparison with analytical results. This technique simply relies on a source term within the energy equation and is equivalent to a Rayleigh-style heating technique in analysis. Specifically, in this study, two different heating schemes were used and examined in the combustor. Initially a single "heating block" was used that consisted of a single uniform (uniform heat per unit volume) heating zone in the combustor. Because of the area ratio in the combustor, and the fact that this particular heating option in VULCAN is performed on a per volume basis, this configuration produced more temperature rise at the rear of the combustor, i.e. one could view it as essentially indicative of a case relying on 'downstream' scheduled injection and combustion. A second setup (somewhat more representative of the mixing/combustion expected in an engine with injection near combustor entrance) was employed that used four heating blocks, each of which with a different percentage of the total heat into the combustor, decreasing in magnitude with axial location throughout the combustor. Both configurations are shown in Fig. 11. Fig. 11 also shows the axial distribution of heat in the combustor for the two cases (keep in mind that the heat is added per volume and that the combustor is expanding). The maximum overall heat rate attempted in the defined combustor configuration was taken based on a heating equivalency to (slightly above) stoichimetric H2-air combustion (fuel heating value of $1.2 \times 10^{8} \mathrm{~J} / \mathrm{kg}$ ). This value, however, could not be reached for the case with distributed heating due to engine unstart, as will be discussed subsequently.

Of specific interest in this section are the flow physics and resulting second-law interactions and dual-mode behavior/coupling which result as overall heating rate is increased throughout the combustor, corresponding, of course, to increasing fuel equivalence ratio in a real system. Therefore, the parametric studies shown and discussed subsequently provide flow features and results for progressively increasing heat rates into the system, with the flow response progressing from fully supersonic, to transition to dual-mode (supersonic with embedded core) with increasing upstream interaction in the isolator, and finally culminating in subsonic flow in the combustor (full ramjet mode) and ultimately engine unstart.

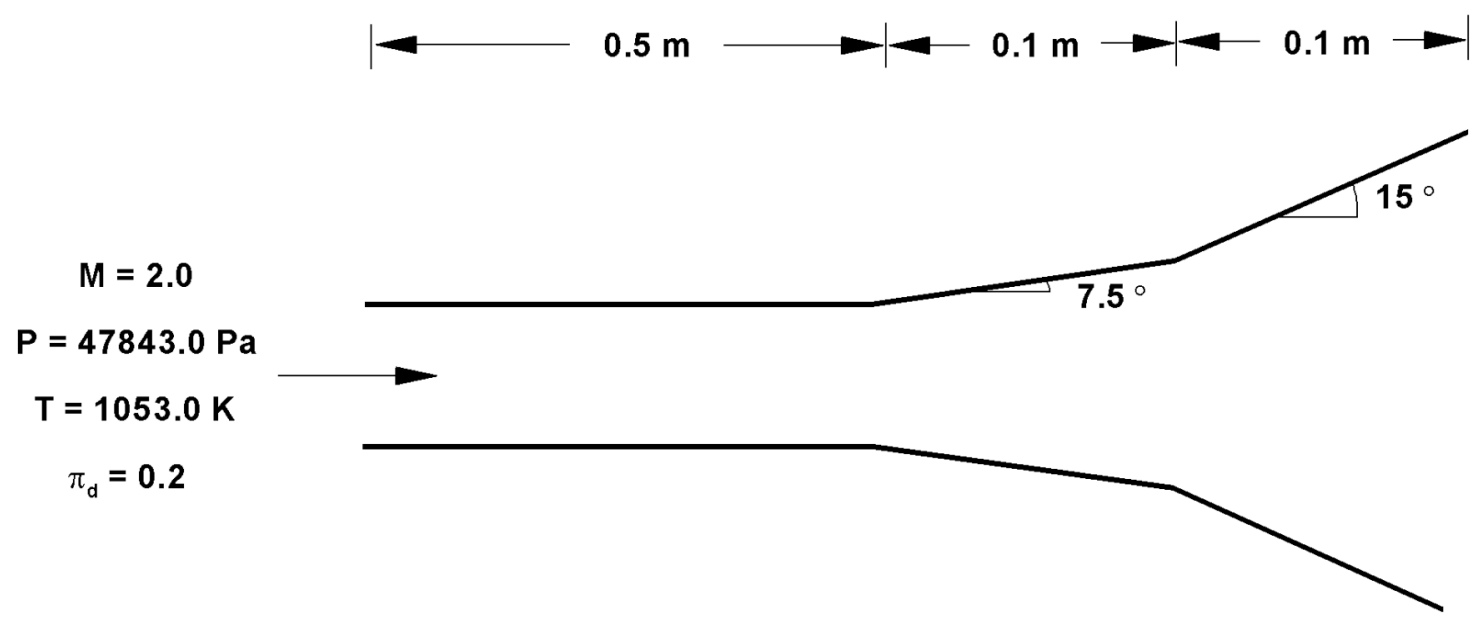

Figure 10. Configuration used in CFD analysis: NOT TO SCALE $\left(\pi_{d}=P_{t 2} / P_{t i}\right)$ 

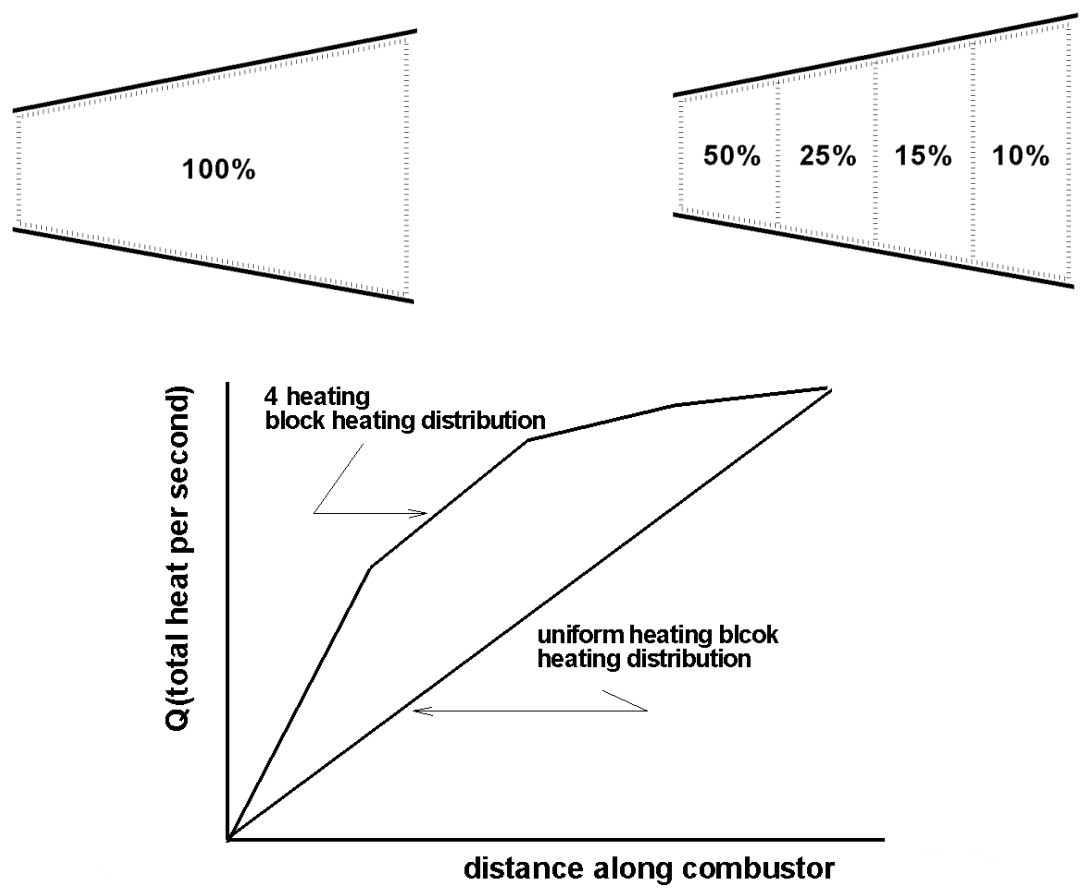

Figure 11. Heating block configurations used; heat distribution along combustor

\section{Results of CFD Parametric Study for Uniform Heat Distribution in Combustor}

This section describes the general flow-field characteristics obtained utilizing the described configuration for the case with uniform distribution of volumetric heating rate with progressively increasing heating rates tested in the CFD.

Figure 12 shows a sequence of contours of flow Mach number in the modeled domain for six different overall heating rates selected from the results of the parametric study $(4,10,12,14,16$, and 17 MWatts). Also shown on each contour field is the sonic line, i.e. the line defined where the local flow is Mach 1. The 4 MWatt case has no subsonic flow except in the boundary layers at the wall, i.e. the flow is fully supersonic and attached everywhere. Between 4MW and 10MW, the flow begins to distort, first within the combustor itself (i.e. distortion and low velocity regions adjacent to the combustor walls develop first in the combustor.) This can be seen in the 10MW contours which shows large low velocity regions of flow adjacent to the boundaries as evidenced by the sonic line these low velocity regions are located mainly in the combustor. This indicates that for the modeled case with uniform distribution of heat (significant heat being deposited in the aft region of the combustor), the forward region of the combustor itself is essentially acting somewhat like an isolator. There is very limited upstream interaction at isolator exit even for the $12 \mathrm{MW}$ case as shown and there is still a 'supersonic' core although most of the combustor flow-field is now subsonic. However, when the heat rate is increased to $14 \mathrm{MW}$, the flow becomes fully subsonic in the latter part of the combustor, i.e. no supersonic core exists. There is also now significant upstream interaction occurring in the isolator with attendant losses and flow compression at isolator exit. It can be seen that the thermal throat anchors upon the combustor/nozzle interface as it should (since it is at this location that both greater area expansion begins and heating ceases - see earlier analytical section). With $16 \mathrm{MW}$ added in the combustor, the isolator flow-field is dominated by upstream-propagating interaction and the flow is completely subsonic even in the latter part of the isolator. Note the expanding and contracting regions of supersonic flow as it moves through the isolator. Note also that the flow in the combustor is now fully subsonic with downstream thermal throat at combustor/nozzle break, i.e. it is operating fully in ramjet mode. The $17 \mathrm{MW}$ case shows even greater upstream interaction in the isolator and any additional heat above this amount results in CFD-predicted engine unstart. 


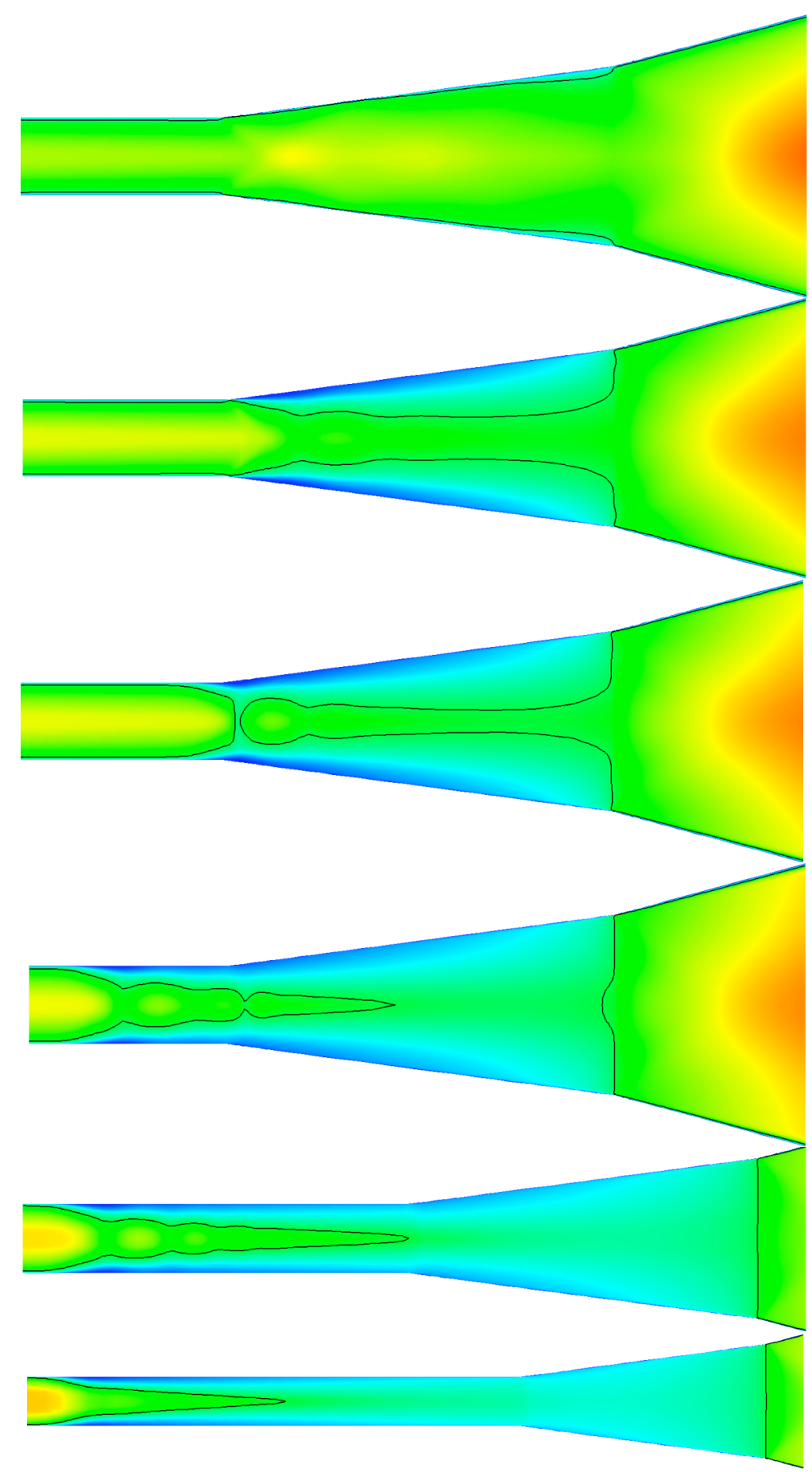

Figure 12. Contours of Mach number (also sonic line) for various total heating rates for uniform heating per volume CFD-generated flow-fields $(4,10,12,14,16,17$ MWatts)

The axial distribution of one-dimensionalized Mach number (stream-thrust averaged) for the CFD results are shown in Fig. 13 for various heating amounts. Although the one-dimensionalized Mach number is not a rigorous quantity due to thermodynamic issues associated with the one-dimensionalization process, it nevertheless provides a qualitative measure of what is happening in the flow-fields. The 'chatter' in the Mach number lines in Fig. 13 is due to the one-dimensionalization as well as mixed-mode flow in the combustor and isolator. Fig. 13 essentially reinforces the physical interpretations made for Fig. 12 and clearly shows the transition from fully supersonic mode, to dual-mode supersonic core, to full ramjet with highly distorted isolator, to incipient unstart. 


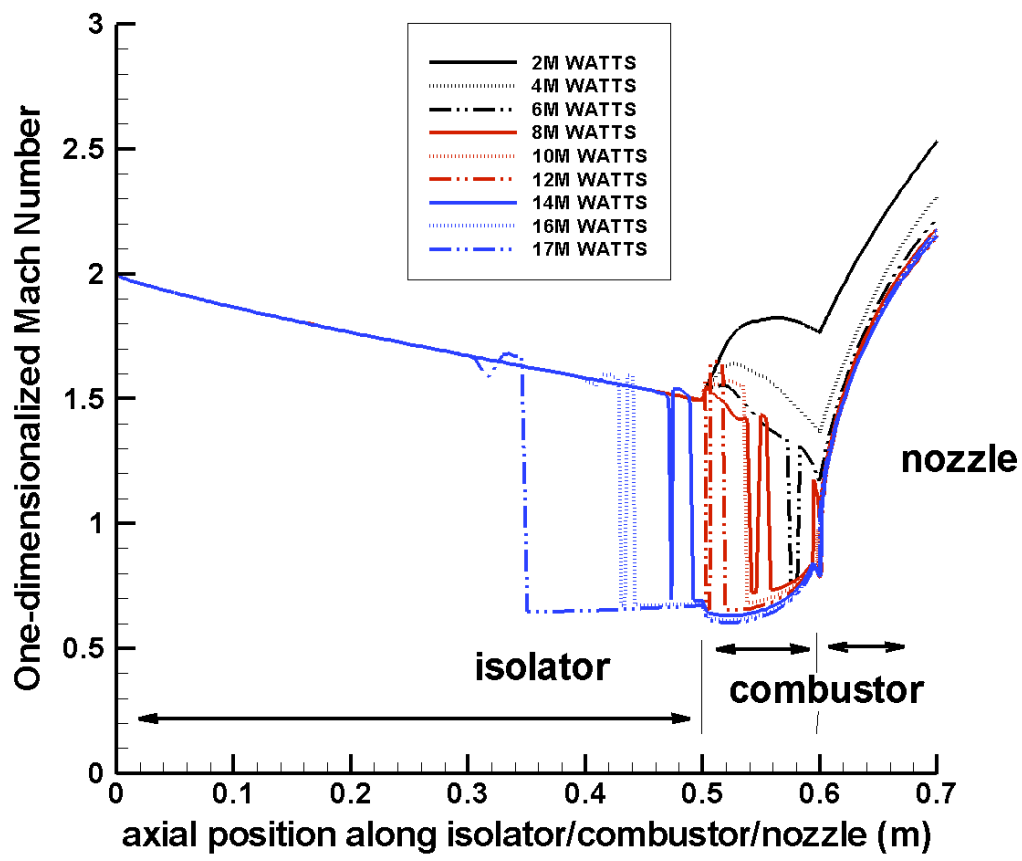

Figure 13. One-dimensionalized Mach number versus distance along isolator/combustor/nozzle

\section{Second-Law Analysis of Parametric CFD Study for Uniform Heat Distribution in Combustor}

This section describes second-law characteristics for the parametric CFD study with uniform heating and relates the results to the fundamental choking limit analysis developed in the earlier sections of this work.

Fig. 14 provides the axial distributions of the cumulative entropy increase due to irreversibilities for the cases with uniform heating. Recall that any entropy increase associated with total pressure decrease is considered as irreversible. This means that all additional entropy generation which is associated with the fact that the heat is added at finite Mach number rather than at the total temperature of the fluid (zero Mach number) is here book-kept as inherently irreversible (i.e. as lowering the total pressure). Therefore the entropy increment as shown in Fig. 14 does not include the entropy increase associated with the heat addition had it occurred ideally, i.e. at zero Mach number. Because the walls are adiabatic, all entropy increase is either due to internal irreversibilites/non-ideal heat addition (i.e. what is shown in Fig. 14) and the entropy increase associated with ideal heat transfer. As can be seen, the flow at isolator entrance has a cumulative entropy rate due to irreversibilities (as measured from freestream entropy) of $1900 \mathrm{~J} / \mathrm{K}-\mathrm{sec}$; this is fixed for all cases with the engine started since the inlet total pressure recovery is fixed at 0.2. The nominal entropy rise through the isolator due to friction and other losses is very close to that expected from a normal shock at Mach 2. This indicates that for the chosen configuration, there will be little 'room' for losses in the isolator before it will unstart. The entropy increase for the case with no heat addition (0 Watts) is associated with friction and weak boundary layer shocks and reflected shocks within the isolator/combustor as well as internal heat transfer between adjacent streamtubes. As can be seen in this figure, upstream interaction in the isolator occurs for overall heating loads of $12 \mathrm{MWatts}$ and greater - the combustor entrance value of the entropy is seen to be progressively higher with increasing heat release due to isolator losses - however, as mentioned above, there is little 'room' in the isolator for losses. As heat is increased to $4 \mathrm{MW}$, (recall that the flow for that case is still fully supersonic with no blockage/distortion), the total irreversibility increases as expected and is maximized for 4 MW. Very significantly, however, for heating rates higher than 4 MW (i.e. when the dual-mode system is transitioning between full supersonic and distorted supersonic) the irreversibility actually decreases and in fact decreases dramatically with increasing heating rate in the combustor. This results in, for example, the $16 \mathrm{MW}$ case actually having significantly less irreversibility than the $4 \mathrm{MW}$ case. Hence, if one examines the same plot with engine specific impulse contours superimposed (as described in previous sections), it can be expected that the 16 MW case will have significantly higher specific impulse than the 4 MW case (as well as higher specific thrust, as expected). 
The discussion/interpretation made in earlier analytical sections fully explains the second-law behavior of this multi-dimensional flow. For supersonic flow, increasing heat addition generates higher Rayleigh-type losses. However, with enough downstream heat release, the supersonic flow begins to develop lower velocity regions associated with increasing heat release and increasing adverse pressure gradient; it then distorts and the flow core (confined) flow is hence at lower Mach number. This distortion (nominally upstream but in reality a complex threedimensional surface) occurs with some additional losses of course (oblique shock trains, etc.) but the lower Mach number heat addition has even less Rayleigh-type loss, hence overall total pressure loss actually drops (or equivalently total system irreversible entropy increase is less) even though more heat is being added. Eventually, the flow at isolator exit/combustor entrance becomes subsonic with even less entropy associated with the downstream heating such that the overall cumulative (irreversible) entropy rise continues to decrease with increasing heat. Eventually, however (if the amount of heat rate added downstream becomes large enough), the increased distortion (with resultant increased irreversibility) in the isolator which is required to initiate a physical heating line in the combustor with thermal throat at combustor exit itself becomes too large (nominally larger than the isolator entrance normal shock limit). The isolator cannot handle its own loss (even though the combined irreversibility in isolator and combustor is actually smaller) and the engine then unstarts.

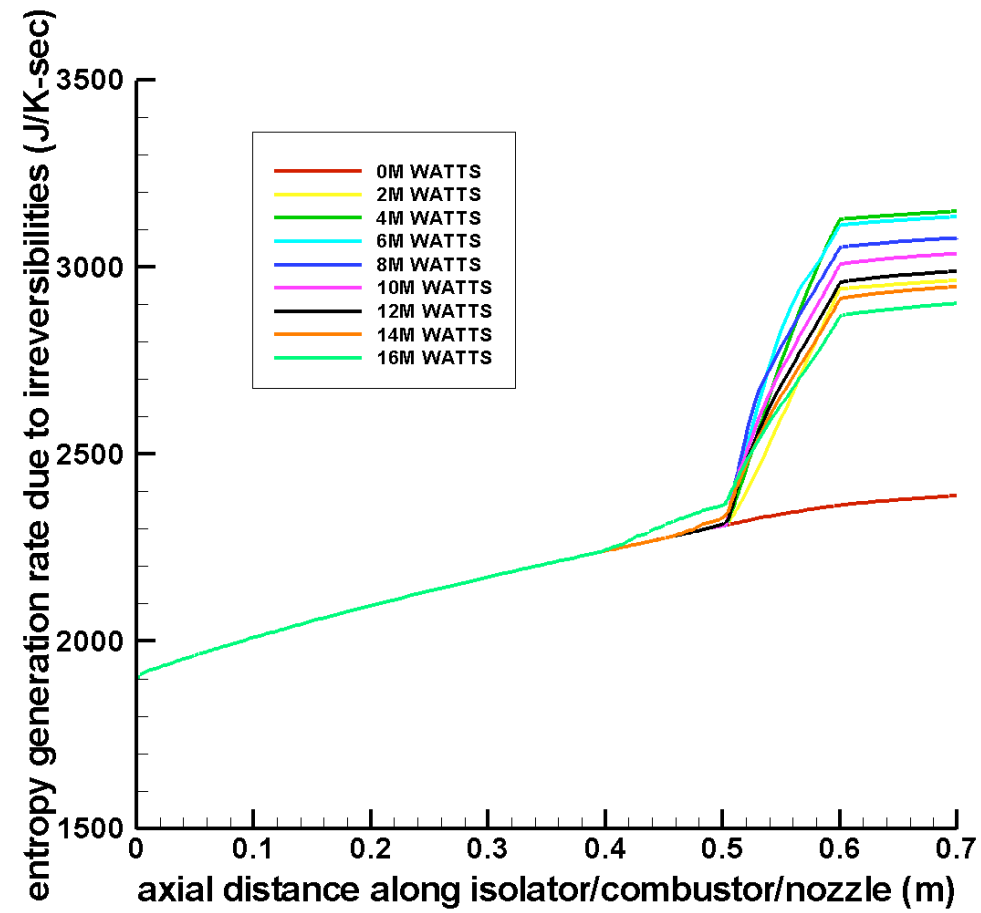

Figure 14. $S_{\text {irr }}$ (rate) versus axial distance for isolator/combustor/nozzle for uniform volumetric heating cases from CFD parametric study

Shown in Fig. 15 are the 'solution trajectories' in terms of heat release versus entropy due to irreversibilities taken from the various 2-D CFD solutions for uniform heat addition, specifically represented by the lower (black) ray family of lines (each line corresponding to the indicated overall heating rate). These lines represent the local cumulative heating (heating parameter) versus cumulative irreversibility (entropy parameter) as the flow progresses through the combustor. This set of lines clearly shows the physics discussed above, i.e. the maximum in irreversible entropy is observed at $4 \mathrm{MW}$ followed by a significant and progressive decrease in irreversibility for higher heating rates. The $6 \mathrm{MW}$ trajectory line shows a clear supersonic to subsonic heating transition (note the distinct decrease in slope in that line) in the mid-range of the combustor. Subsequent higher heating rate lines are largely (and increasingly) subsonic (in bulk). The upper (red) ray or family of lines is simply the analytical choking limits for the given geometry and heating distribution. Note that for low heating rates, the actual flow remains unchoked (i.e. the cumulative combustor exit irreversible entropy amount is well below that required to choke the flow at any given heating rate), but as the heating rates are increased the solution trajectory approaches the choking limit line at 
combustor exit until there is essentially exact correspondence for heating rates of $10 \mathrm{MW}$ and higher, indicating thermal choking occurring at combustor exit (as also seen on prior contour plots). Recall what is happening - the flow at isolator exit is experiencing higher losses (associated with distortion) in order to sustain the (even larger) reduction in the required loss in the combustor. Eventually, the isolator cannot sustain the required loss and the engine unstarts. This is seen on the 'detail' of the solution trajectories as shown in Fig. 16 for regions near the isolator exit/combustor entrance. Note that the heating rate cases up to $8 \mathrm{MW}$ are supersonic entering the combustor with attendant high losses in the combustor. The $10 \mathrm{MW}$ case also begins supersonic but is transitioning very rapidly to subsonic. Higher heating cases are subsonic with much reduced losses downstream in the combustor however note that the total pressure at isolator exit is reduced for these cases (with higher isolator losses for higher downstream heating rates as discussed earlier).

Although not shown here, an analytical solver such as discussed in the previous analytical section of this work can be used which tracks both the fully supersonic ( 2 and $4 \mathrm{MW}$ cases with no significant distortion or area constriction assumed at isolator entrance) and the fully subsonic (ramjet mode) cases (12 MW cases and higher). It also provides good agreement for the $6 \mathrm{MW}$ case until the transition from supersonic to subsonic combustion mentioned above - for that case and the $8 \mathrm{MW}$ and $10 \mathrm{MW}$ case, there is a great deal of distortion in the combustor itself such that the simplified area constriction modeling used in the analytical solver is not accurate). Although the analytical solver works well for the full ramjet mode, it must be initiated with some relatively small distortion at isolator exit (a 0.95 area constriction for $16 \mathrm{MW}$ case) as well as reduced total pressure at isolator exit as observed from the CFD. There is no significant required constriction at isolator exit for the $17 \mathrm{MW}$ case and the analytical solver predicts engine unstart at 17.5 MW heating rate which is identical to the CFD results.

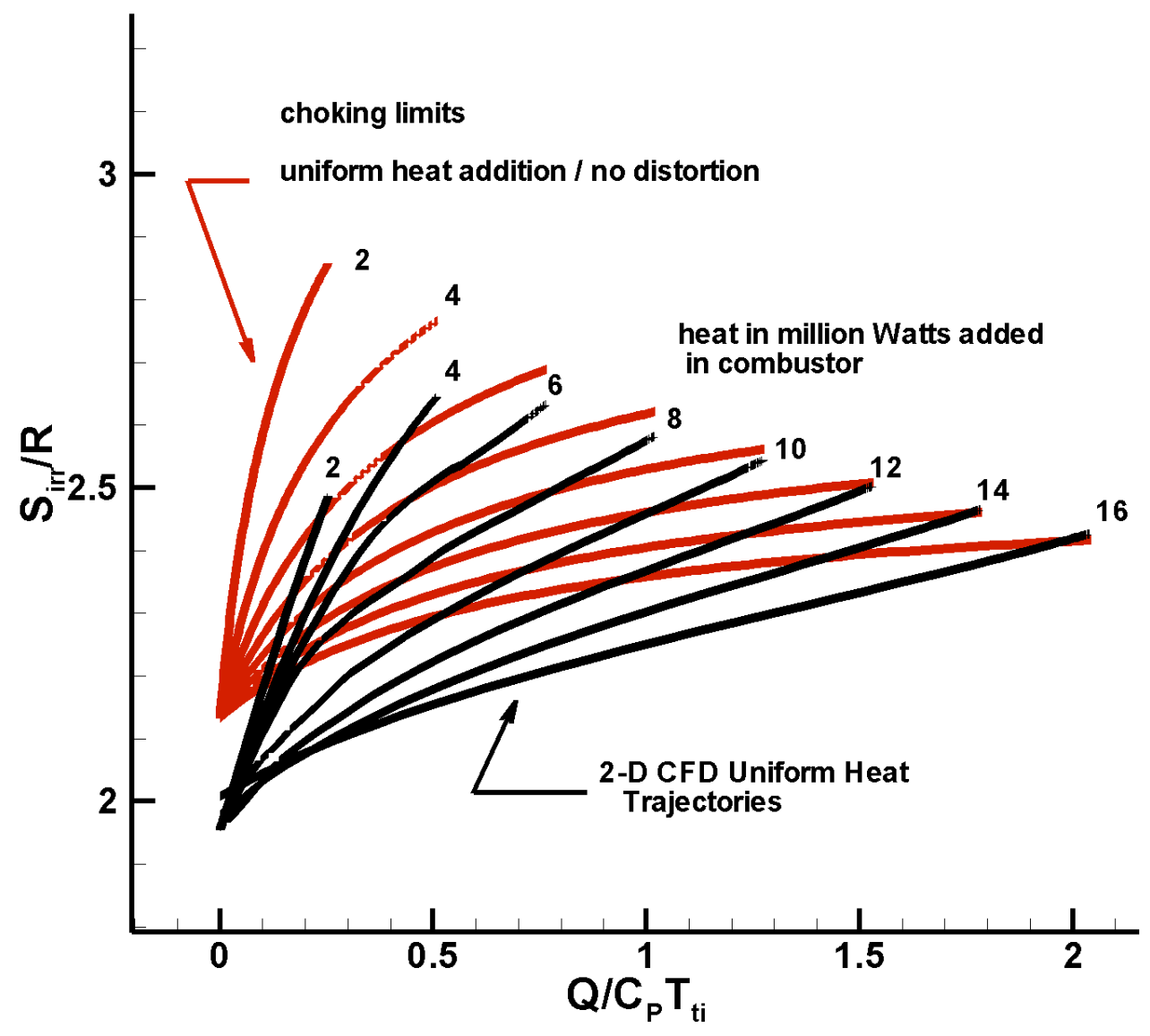

Figure 15. Heating versus irreversibility plot showing CFD solution trajectories and analytical choking limits for uniform volumetric heating cases 

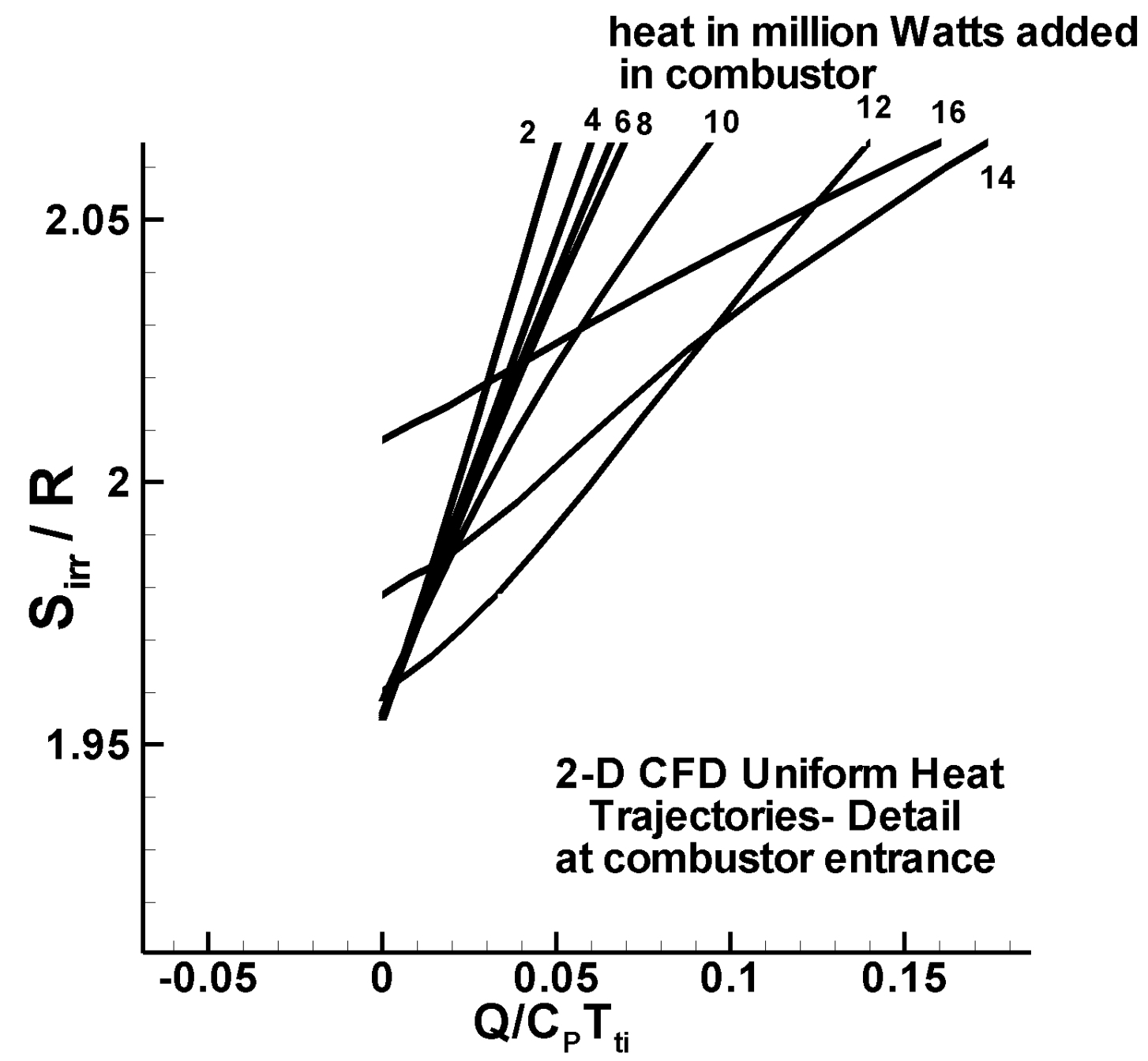

Figure 16. Heating versus irreversibility plot showing CFD solution trajectories and analytical choking limits for uniform volumetric heating cases: Detail near combustor entrance

\section{Results of CFD Parametric Study for Distributed (4 Block) Heat Distribution in Combustor}

This section describes the general flow-field characteristics obtained utilizing the described configuration for the case with distributed (4 block) volumetric heating rates, again for flow-fields with progressively increasing heating rates. Only sample flow-field results are shown for brevity although heating rates from 1 to $8 \mathrm{MW}$ in increments of 1 MW were examined in the parametric study. Note that this distributed heating more closely mimics a case with fuel injection and reaction upstream (forward) in the combustor than the uniform heating rate cases discussed in the previous sections. For this reason, the isolator is effectively coupled with the combustor at much lower heating rates.

Figure 17 shows contours of Mach number for the $6 \mathrm{MW}$ heating rate. Note that the sonic line is shown on this plot (as well as subsequent contour plots) in order to distinguish low and high velocity regions and to show thermal choking. The adverse pressure gradient resulting from the heating causes low velocity regions to form on the top and bottom walls near the exit of the isolator. However, the amount of heat deposited is not enough to cause thermal choking, and a supersonic core flow remains throughout the isolator and combustor.

The second Mach number contour plot (Fig. 18) is for the flow-field with a heating rate input of 7 MW. This amount of heat is sufficient to cause thermal choking, as can be seen where the sonic line detaches at the front of the combustor. The pressure difference between the initially undistorted flow in the isolator and the supersonic heated flow in the combustor has become large enough to dramatically increase the size of the low velocity regions in the latter part of the isolator. The originally fully supersonic and undistorted flow in the isolator now couples with the 
flow in the combustor by forming an oblique shock train which increases the static pressure through compression and expansion waves. The flow at isolator exit is highly distorted.

The third Mach number contour plot (Fig. 19) is for the case in which a total of $8 \mathrm{MW}$ has been deposited into the combustor. Most of the flow in the isolator is subsonic, due to the large pressure gradient and thermal choking. If more heat than $8 \mathrm{MW}$ is deposited in the combustor, the configuration unstarts.

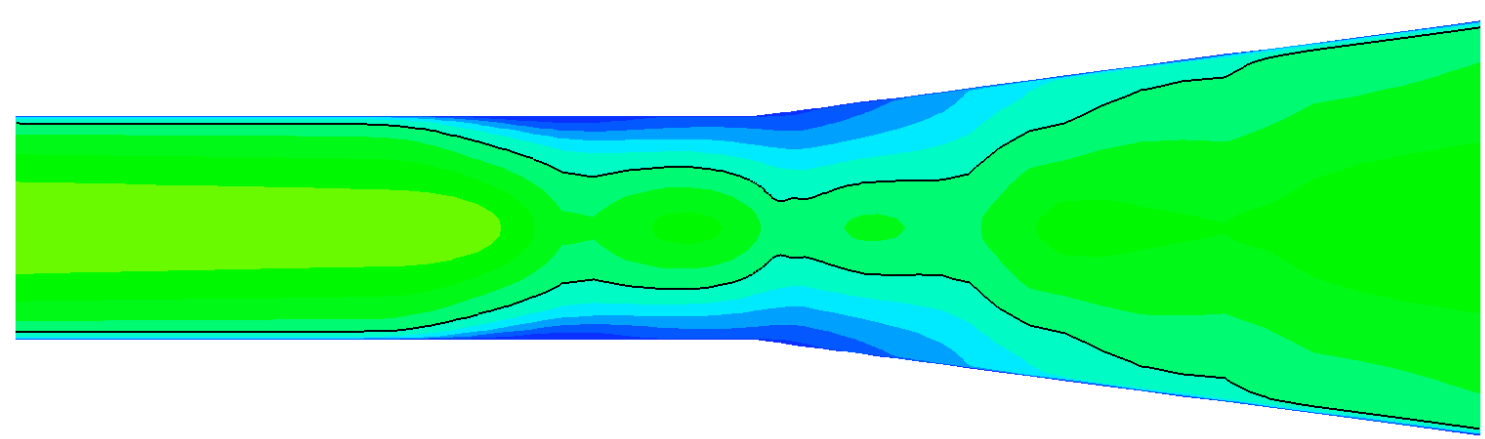

Figure 17. Contours of Mach number and sonic line for 6 Million Watts total heat addition - distributed heat CFD parametric study

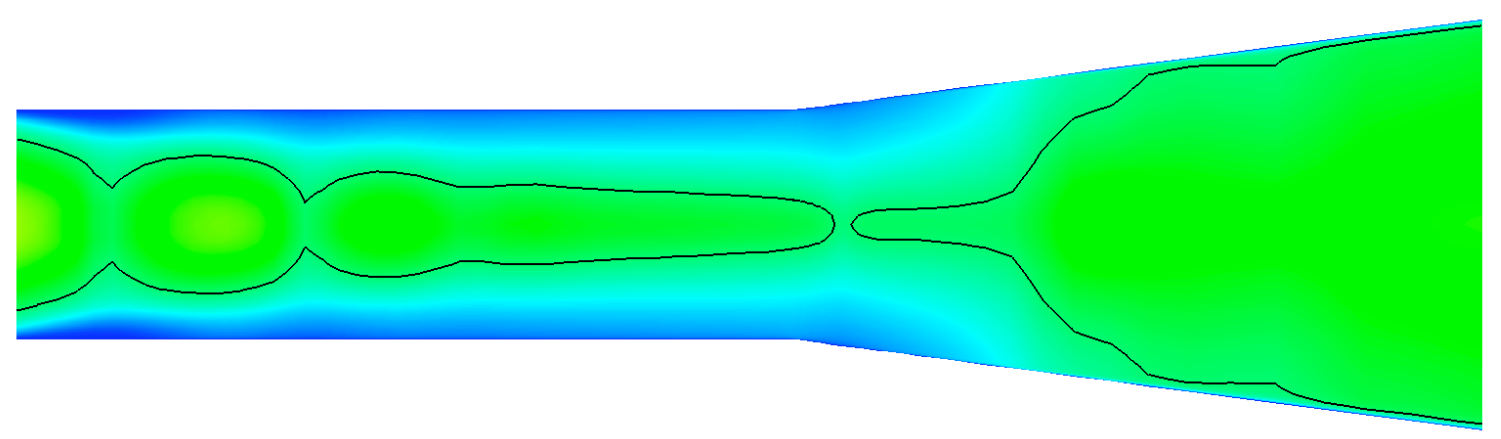

Figure 18. Contours of Mach number and sonic line for 7 Million Watts total heat addition - distributed heat CFD parametric study

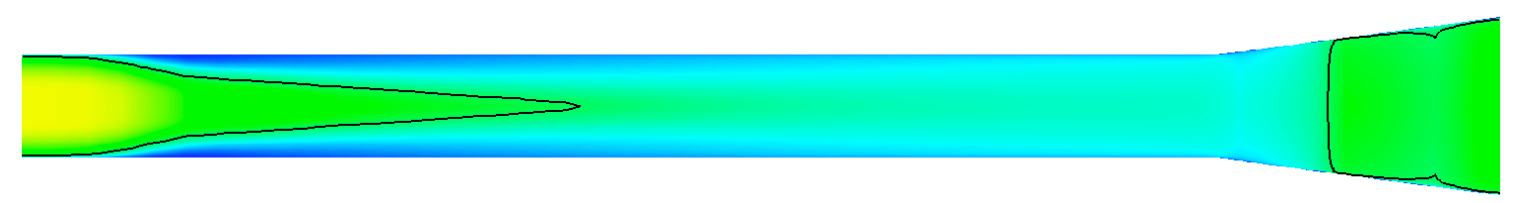

Figure 19. Contours of Mach number and sonic line for 8 Million Watts total heat addition - distributed heat CFD parametric study

A plot displaying the total cumulative irreversibility as a function of engine length is shown in Fig. 20 for varying combustor heat rates for the distributed heat cases. As stated earlier, the isolator has significant flow distortion for the three highest heating rates, with a corresponding irreversibility increase through the isolator itself. However, the overall irreversiblility is basically flat for heating rates greater than $3 \mathrm{MW}$. Also note that the total irreversibility for the case with $8 \mathrm{MW}$ is actually less than that for $7 \mathrm{MW}$. This is a consequence of the reduction in the Rayleigh losses in the combustor more than countering the increase in isolator losses for that case. 


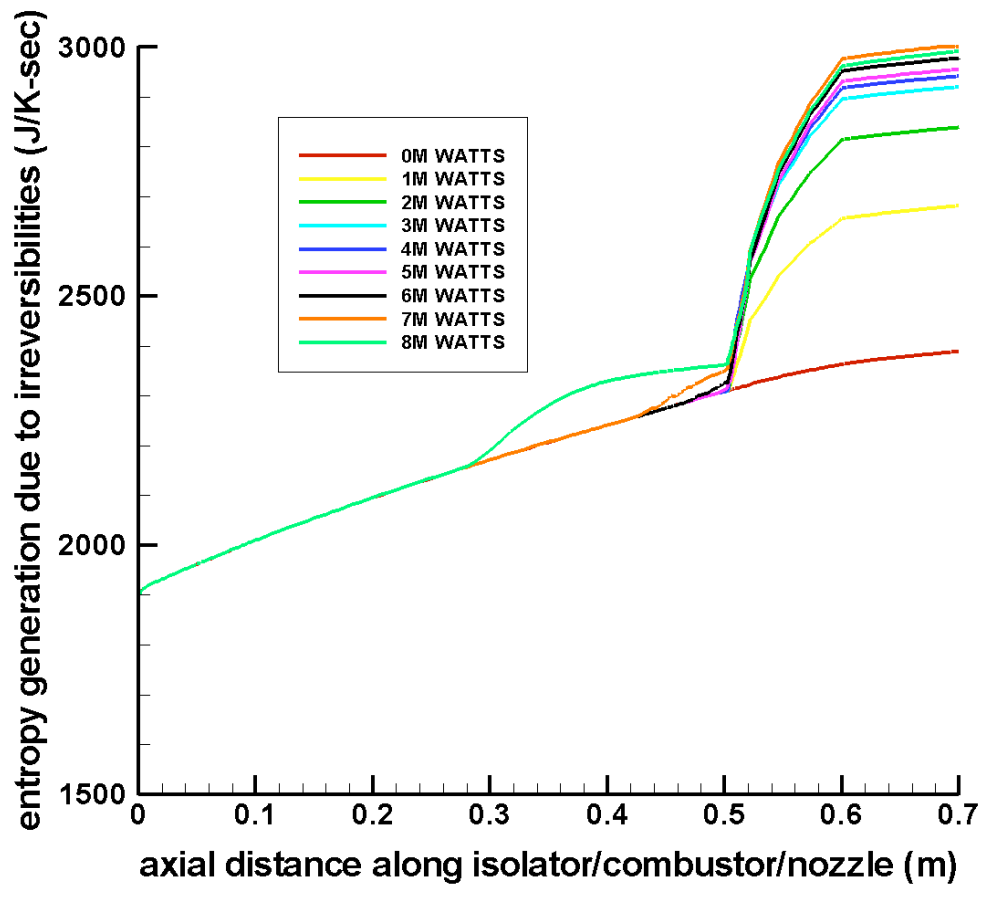

Figure 20. Entropy generation due to irreversibility for variable heating blocks

Figure 21 shows plots of the CFD predicted 'heating trajectories' from the solutions for both distributed and uniform heating rates as described in the previous section (together). It is plainly seen that the uniform heating rate case is superior in providing a much greater range of heat release (stoichimetric equivalent, in fact) for essentially no penalty in irreversible entropy (i.e. total pressure drop). When one considers the contours of $I_{\mathrm{sp}}$ and specific thrust which can be superimposed on this plot, it is significant that the dual-mode system can conceptually provide both higher specific impulse and higher specific thrust for large increases in overall heat release. This plot neatly characterizes the performance advantage (necessity) of staging the fuel injection in a dual mode system. 


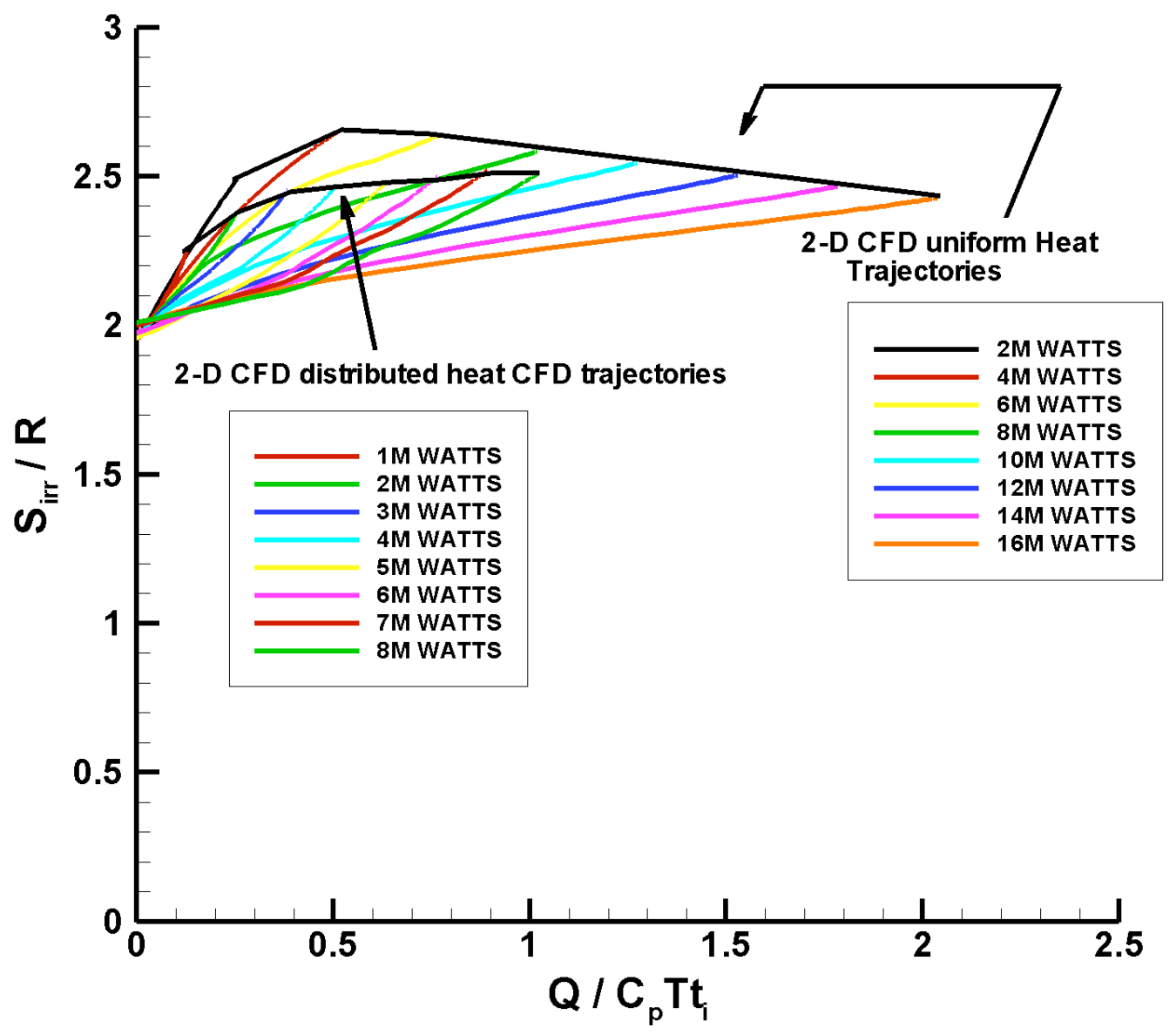

Figure 21. Heating trajectories for both uniform and distributed heat in combustor (compilation of CFD results)

Figure 22 demonstrates results from the previously described choking limits analysis for cases with 6 and $8 \mathrm{MW}$ heat rate deposited into the combustor, when appropriate area constriction at combustor entrance is used (as indicated.) Note that the choking limit line shows thermal choke (i.e. it intersects or just reaches the actual CFD heating trajectory) for the $8 \mathrm{MW}$ case when an area constriction of 0.94 is assumed to exist at combustor entrance. It does not converge thermally choke without distortion as shown by the line for 8 MW choking limit without distortion (i.e. it does not tangentially intersect - or touch - the 8 MW CFD heating line without distortion). Similarly, the $6 \mathrm{MW}$ choking limit line must be initiated with an area constriction of 0.85 in order for the thermal choke observed in the associated CFD solution to exist. Interestingly, the thermal choke locations predicted with the simplified heating choking limit analysis used here correspond very well to the CFD-predicted thermal chokes, as observed from one-dimensionalized representations of the flow-fields. 


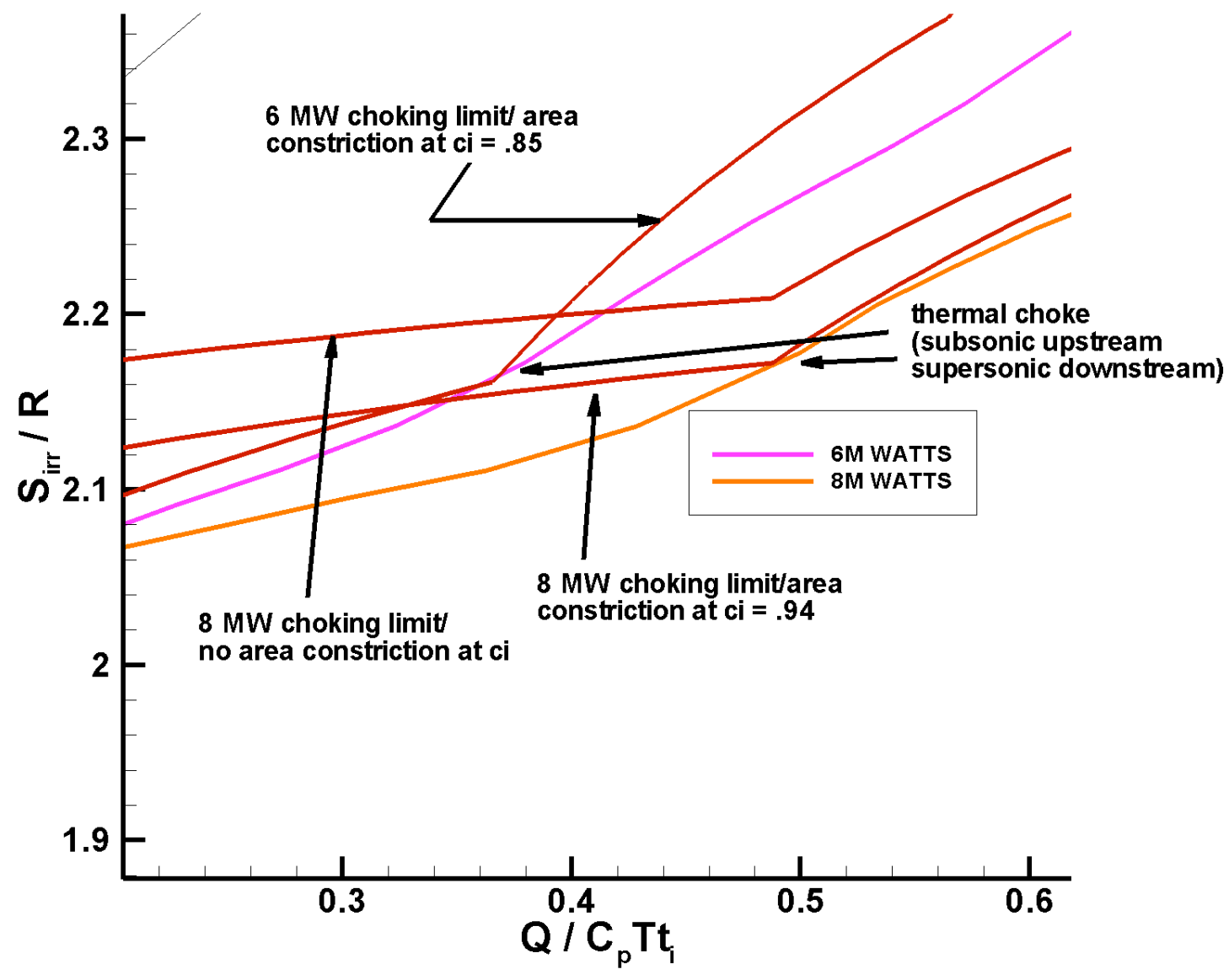

Figure 22. CFD heating trajectories and required analytical choking limit lines showing required distortion for 6 and $8 \mathrm{MW}$ cases for distributed heating in parametric CFD

\section{Conclusion}

Dual-mode scramjet operability and performance characteristics are analytically examined from fundamental principles. Specifically, the problem is analyzed using entropy generation due to irreversibilies (including entropy generation associated with non-ideal heat interaction), heat interaction, and area ratio distribution in simplified configurations. Overall and local choking limits and associated mode transition phenomena are illustrated utilizing entropy and heat plots; these plots are coupled with actual fluid dynamic histories shown on the same plots in order to provide explanation and clarification of important issues in the dual-mode regime. The analysis depicts and quantifies the shifting balance of losses between isolator and combustor which can actually yield significantly lower irreversibility (and hence increased performance) for increasing heat into a given configuration. The two effects which determine isolator performance and buffering capability (and hence engine performance) are degree of distortion and the losses incurred by that distortion. Additionally, overall engine performance in terms of engine specific impulse and engine specific thrust can be superimposed on the irreversibility versus heat plots in order to assess the performance 'trajectory' of various configurations and design trades and the causes and effects of mode transition. The characteristics of supersonic distorted dual-mode behavior (separated flow in isolator and combustor with supersonic core flow) can also be addressed using this type of analysis by modifying the technique to handle distorted (core) flow.

Basic two dimensional CFD simulations are then performed in a parametric study of a generic dual-mode system in which the dual-mode problem is 'deconstructed' by modeling the combustion-generated heat release in a real engine by using 'heating blocks' in the combustor along with adiabatic walls and perfect gas. This reduces the 
complexity encountered in a full simulation and allows a more fundamental assessment of the basic issues of thermal choking, upstream interaction, and mode transition. Two heating block configurations are tested; the first a uniform volumetric heating zone located in the combustor. Overall heating rates are input ranging from 2 to 17 MW. This configuration emulates (approximately) a linear heating distribution (i.e. similar to a downstream scheduled heat release in an engine). Significantly, it is shown that irreversibilities actually decrease with increasing heat across the range (until the engine unstarts); this indicates increasing engine specific impulse and engine specific thrust as the isolator interaction evolves. The second heating block configuration is sub-divided into four blocks with progressively decreasing volumetric heats in the downstream direction. This (approximately) modeled more upstream-biased heat release, i.e. forward injection and reaction in a scramjet engine. This configuration showed significantly less heating capability (isolator buffering) than the first configuration due to thermal choking and engine unstart issues.

This paper provides a fundamental examination of the dual-mode engine problem by analyzing the important characteristics of thermal choking limits and mode transition utilizing entropic analysis and the isolator response. By using the most basic drivers on engine performance and operability (entropy, heat, and configuration descriptors) as the main parameters of interest, the behavior of the dual mode system is clarified and quantified.

\section{Acknowledgments}

This work was partially supported under the AFOSR summer researchers (graduate student) program. Thanks are due to Dr. David Moorhouse and Dr. Jose Camberos of AFRL as well for their support and encouragement in all phases of this and related work.

\section{References}

[1] Curran, E. T., and Stull, F. D., "The Utilization of Supersonic Combustion Ramjet Systems at Low Mach Numbers", Aero Propulsion Laboratory, RTD-TDR-63-4097, Jan. 1964.

[2] Billig, F.S., and Dugger, G.L., "The Interaction of Shock Waves and Heat Addition in the Design of Supersonic Combustors", Proceedings of the $12^{\text {th }}$ Symposium on Combustion, Combustion Institute, Pittsburg, PA, 1969, pp. $1125-1134$.

[3] Billig, F.S., Dugger, G.L., and Waltrup, P.J., "Inlet-Combustor Interface Problems in Scramjet Engines", Proceedings of the $1^{\text {st }}$ International Symposium on Air-Breathing Engines, Marseilles, France, June 1972.

[4] Waltrup, P.J. and Billig, F.S., "Prediction of Precombustion Wall Pressure Distribution in Scramjet Engines", Journal of Spacecraft and Rockets, Vol. 10, No. 9, 1973, pp. 620-622.

[5] Waltrup, P.J. and Billig, F.S., "Structure of Shock Waves in Cylindrical Ducts", AIAA Journal, Vol. 11, No. 9, 1973, pp. 1404-1408.

[6] Komuro, T., Kudo, K. Masuya, G., Chinzei, N. Murakami, A., and Tani, K., "Experimental on a Rectangular Cross Section Scramjet Combustor" (in Japanese), National Aerospace Lab, NAL TR-1068, Tokyo, Japan, 1990.

[7] Murakami, A., Komuro, T., and Kudo, K., "Experiment on a Rectangular Cross-Section Combustor (II) - Effects of Fuel Injector Geometry" (in Japanese), National Aerospace lab, NAL TR-1220, Tokyo, Japan, 1993.

[8] Chinzei, N., Komuro, T., Kudou, K., Murakami, A., Tani, K., Masuya, G., and Wakamatsu, Y., "Effects of Injector Geometry on Scramjet Combustor Performance", AIAA Journal of Propulsion and Power, Vol. 9, No. 1, Jan-Feb. 1993, pp. 146-152.

[9] Mizobuchi, Y., Matsuo, Y. and Ogawa, S., “ Numerical Estimation of Turbulence Temperature Fluctuation Effect on Hydrogen-Oxygen Reaction Process”, AIAA Paper 97-0910, January 1997.

[10] Matsuo, Y., Mizobuchi, Y. and Ogawa, S., "Parallel Numerical Simulation of Compressible Free Shear Layers in a Scramjet Engine", AIAA Paper 98-0963, January 1998.

[11] Rodriguez, C., Riggins, D., and White, J., "Three-Dimensional Effects in Modeling of Dual-Mode Scramjets", AIAA Paper-2000-3704, July, 2000.

[12] Heiser, W., and Pratt, D., Hypersonic Airbreathing Propulsion, AIAA Education Series, AIAA, 1994.

[13] Ortwerth, P., "Scramjet Flowpath Integration", Chapter 17 in Scramjet Propulsion, Progress in Astronautics and Aeronautics, Curran and Murthy (Editors), Volume 189, AIAA, 2000. 